\title{
El acoplamiento excitación-contracción en el músculo esquelético: preguntas por responder a pesar de 50 años de estudio
}

\author{
Juan Camilo Calderón-Vélez ${ }^{1,2}$, Lourdes Carolina Figueroa-Gordon² \\ 1 Departamento de Fisiología y Bioquímica, Grupo de Fisiología del Ejercicio, Facultad de Medicina, \\ Universidad de Antioquia, Medellín, Colombia. \\ 2 Laboratorio de Fisiología Celular, Centro de Biofísica y Bioquímica, Instituto Venezolano de Investigaciones \\ Científicas, Estado Miranda, Venezuela.
}

El mecanismo de acoplamiento excitación-contracción fue definido en el músculo esquelético como la secuencia de eventos que ocurre desde la generación del potencial de acción en la fibra muscular hasta que se inicia la generación de tensión. La regulación e interacción de dichos eventos entre sí ha sido estudiada durante los últimos 50 años utilizando diferentes técnicas, con las cuales se estableció la importancia y origen del ion calcio como activador contráctil, se conocen las principales proteínas involucradas y se inició el estudio de la base ultraestructural y de la regulación farmacológica; además, hay evidencias de que el acoplamiento excitación-contracción se altera en diferentes situaciones como en el envejecimiento, en la fatiga muscular y en algunas enfermedades musculares. Sin embargo, aún hay varias preguntas por responder: ¿cómo es el desarrollo y envejecimiento del mecanismo de acoplamiento excitación-contracción?, ¿cuál es su papel en la fatiga muscular y en algunas enfermedades musculares?, ¿cuál es la naturaleza de la interacción entre diferentes proteínas involucradas en el acoplamiento excitación-contracción? La presente revisión describe el acoplamiento excitación-contracción en el músculo esquelético y las técnicas utilizadas para su estudio como introducción para discutir algunas de las preguntas que aún falta por responder al respecto.

Palabras clave: músculo esquelético, contracción muscular, relajación muscular, calcio, canal liberador de calcio, canales de calcio tipo L, receptor de rianodina, fatiga muscular.

Excitation-contraction coupling in skeletal muscle: questions remaining after 50 years of research

The excitation-contraction coupling mechanism was defined as the entire sequence of reactions linking excitation of plasma membrane to activation of contraction in skeletal muscle. By using different techniques, their regulation and interactions have been studied during the last 50 years, defining until now the importance and origin of the calcium ion as a contractile activator and the main proteins involved in the whole mechanism. Furthermore, the study of the ultrastructural basis and pharmacological regulation of the excitation-contraction coupling phenomenon has begun. The excitation-contraction coupling is thought to be altered in situations as ageing, muscle fatigue and some muscle diseases. However, many questions remain to be answered. For example, (1) How excitation-contraction coupling develops and ages? (2) What role does it play in muscle fatigue and other diseases? (3) What is the nature of the interaction between the proteins believed to be involved? The present review describes excitation-contraction coupling in skeletal muscle and techniques used to better understand it as an introduction for discussing unanswered questions regarding excitation-contraction coupling.

Key words: muscle, skeletal; muscle contraction, muscle relaxation, calcium, ryanodine receptor calcium release channel, dihydropyridine receptors, muscle fatigue 
El fenómeno de acoplamiento excitación-contracción fue definido por Alexander Sandow como la secuencia de eventos que ocurre desde la generación del potencial de acción en la fibra muscular hasta que se inicia la generación de tensión $(1,2)$. Desde sus trabajos clásicos en músculo esquelético hasta ahora han pasado más de 50 años, durante los cuales las técnicas para el estudio de este fenómeno han mejorado su poder de resolución y discriminación a nivel molecular, y se ha acumulado una gran cantidad de información sobre sus bases morfológicas, su importancia fisiológica y su modulación farmacológica (3), inicialmente en anfibios y recientemente en mamíferos. Ciertos aspectos se han vuelto a investigar utilizando equipos que ofrecen mejor resolución temporal y espacial, y compuestos como los indicadores fluorescentes de calcio $\left(\mathrm{Ca}^{2+}\right)$ rápidos (de baja afinidad), que permiten evaluar la cinética de los movimientos de $\mathrm{Ca}^{2+}$ de forma más cercana a lo que sucede en la célula. Algunas preguntas interesantes apenas se han empezado a abordar en la última década con el desarrollo de técnicas más potentes de investigación como la biología molecular.

Persisten también importantes preguntas concernientes al desarrollo y regulación del mecanismo de acoplamiento excitación-contracción en fibras de músculo esquelético, su alteración y papel en fenómenos como el de fatiga y envejecimiento muscular, la naturaleza de la interacción de algunas moléculas entre sí dentro de la secuencia de eventos de dicho acoplamiento y su posible modulación farmacológica.

\section{El mecanismo de acoplamiento excitación- contracción en el músculo esquelético}

$\mathrm{El}$ ion $\mathrm{Ca}^{2+}$ es un segundo mensajero intracelular en las células eucariotas (4). La homeostasis del $\mathrm{Ca}^{2+}$ celular y su señalización son el resultado de interacciones dinámicas entre mecanismos que

\footnotetext{
Correspondencia:

Juan Camilo Calderón-Vélez, Instituto Venezolano de Investigaciones Científicas, Carretera Panamericana, km 11, Altos del Pipe, Estado Miranda, Venezuela.

Teléfono: (0058) 212-504-1217; fax: (0058) 212-504-1764 jcalderonv00@yahoo.com

Recibido:05/06/08; aceptado:27/11/08
}

conllevan a un incremento en la concentración intracelular de $\mathrm{Ca}^{2+}$ y mecanismos que tienden a disminuirla, mediados por una diversidad de bombas y transportadores que se localizan en la membrana plasmática y en organelos intracelulares, como el retículo sarcoplásmico y la mitocondria, y por proteínas citosólicas que unen $\mathrm{Ca}^{2+}$. En el caso particular de los músculos estriados, los mecanismos de contracción y relajación están regulados por cambios en la concentración del $\mathrm{Ca}^{2+}$ libre citoplásmico (o mioplásmico) (5-9). El fenómeno de acoplamiento excitación-contracción representa una comunicación rápida entre los eventos eléctricos que ocurren en la membrana plasmática o plasmalema y la liberación de $\mathrm{Ca}^{2+}$ del retículo sarcoplásmico, la cual lleva a la contracción muscular (transducción de una señal eléctrica en una respuesta mecánica).

La secuencia de eventos del acoplamiento excitación-contracción en el músculo esquelético involucra: iniciación y propagación de un potencial de acción a lo largo de la membrana plasmática, propagación del potencial a lo largo del sistema de túbulos transversos o túbulos $\mathrm{T}$, detección de los cambios en el potencial de membrana por parte de los receptores de dihidropiridinas (dihydropyridine receptors, DHPR), transmisión de la señal a los receptores de rianodina (ryanodine receptors, RyR) del retículo sarcoplásmico, liberación de $\mathrm{Ca}^{2+}$ del retículo sarcoplásmico, aumento transitorio de la concentración de $\mathrm{Ca}^{2+}$ en el citoplasma, activación transitoria del sistema amortiguador de $\mathrm{Ca}^{2+}$ y del aparato contráctil y recaptura del $\mathrm{Ca}^{2+}$ por el retículo sarcoplásmico $(2,10,11)$.

En las células musculares esqueléticas de anfibio la distribución y conductancia diferencial de iones a través de la membrana, principalmente $\mathrm{K}^{+}$y $\mathrm{Cl}^{\prime}$, genera un potencial de reposo de -90 $\mathrm{mV}$; el interior celular es negativo con respecto al medio externo (12).

El potencial de acción de las fibras musculares se inicia por la acción del neurotransmisor acetilcolina liberado en la placa motora por una neurona motora inferior, lo cual origina una despolarización de la membrana de hasta 
$100 \mathrm{mV}$, mediante cambios de conductancia dependientes de voltaje inicialmente del $\mathrm{Na}^{+} \mathrm{y}$, luego, con cierto retraso, del $\mathrm{K}^{+}(12,13)$.

El potencial de acción generado en la membrana plasmática se propaga longitudinalmente a lo largo de la fibra y transversalmente a través de los túbulos $\mathrm{T}$, mediante un proceso regenerativo y dependiente de sodio $(14,15)$. Los túbulos T son invaginaciones de la membrana plasmática que se extienden transversalmente en las fibras musculares y sirven como medio para llevar información eléctrica desde la superficie hasta el interior de la fibra muscular, particularmente hacia la membrana del retículo sarcoplásmico (16).

En los túbulos T, específicamente en los segmentos asociados con el retículo sarcoplásmico, se encuentran los receptores de dihidropiridinas - canales de $\mathrm{Ca}^{2+}$ tipo $\mathrm{L}$-la estructura conformada por un túbulo $\mathrm{T}$ y los segmentos de retículo endoplásmico que lo flanquean se conoce como tríada-, cuya función está regulada por el potencial de membrana, por lo cual se conocen también como sensores de voltaje, que induce un cambio en su conformación aún no completamente aclarado, que se transmite a los receptores de rianodina (ver adelante) (17-20).

En el músculo esquelético, los receptores de dihidropiridinas interactúan con los de rianodina tipo 1 , los cuales se encuentran en la cisterna terminal del retículo sarcoplásmico, formando las estructuras conocidas como pies. Son homotetrámeros de alto peso molecular ( 560 $\mathrm{kDa}$ ) con un gran dominio citoplásmico y uno transmembrana que permite el funcionamiento de la proteína como un canal de $\mathrm{Ca}^{2+}$ que regula la salida de este ión del retículo endoplásmico hacia el citoplasma (21-24). Su actividad es regulada por el trifosfato de adenosina (ATP), magnesio $\left(\mathrm{Mg}^{2+}\right), \mathrm{Ca}^{2+}$, el estado de oxido-reducción, el estado de fosforilación/desfosforilación y varias proteínas como la calsecuestrina, la calmodulina, la S100A1, la FKBP (FK 506 binding protein) y, posiblemente, por la proteína recién caracterizada SRP-27 (11,21,25-29).

Morfológicamente, cada una de las proteínas de una tétrada de receptores de dihidropiridinas se asocia con cada una de las cuatro subunidades de un receptor de rianodina 1; sin embargo, se reconoce que no a todos los receptores de rianodina 1 en la cisterna terminal del retículo sarcoplásmico corresponde una tétrada de receptores de dihidropiridinas en los túbulos $T$ $(23,24)$. El acoplamiento estructural entre los receptores de dihidropiridinas y los de rianodina constituye las unidades funcionales liberadoras de $\mathrm{Ca}^{2+}$, las cuales se activan en su mayoría de manera simultánea en respuesta a un potencial de acción $(23,24)$. La activación de los receptores de rianodina 1 genera la salida de $\mathrm{Ca}^{2+}$ al citoplasma. Se ha propuesto que el $\mathrm{Ca}^{2+}$ en la periferia del retículo sarcoplásmico activa otros receptores de rianodina no acoplados directamente con una tétrada de receptores de dihidropiridinas, mediante el mecanismo de retroalimentación positiva, inicialmente descrito en músculos de rana, conocido como liberación de $\mathrm{Ca}^{2+}$ inducida por $\mathrm{Ca}^{2+}$ (calcium-induced calcium release, $\mathrm{CICR)}(8,30)$; esto genera una liberación masiva de $\mathrm{Ca}^{2+}$ que produce un incremento transitorio de este catión en el citoplasma de las fibras musculares. La presencia momentánea del $\mathrm{Ca}^{2+}$ en el citoplasma se puede documentar en función del tiempo; el registro que se genera se conoce como transitorio de $\mathrm{Ca}^{2+}$ (ver más adelante).

La salida de $\mathrm{Ca}^{2+}$ del retículo sarcoplásmico puede alcanzar una tasa mayor de 200 umoles/ ms en fibras rápidas de mamífero y generar una concentración citoplásmica de $\mathrm{Ca}^{2+}$ libre cercana a $20 \mu \mathrm{M}$ (31,32); sin embargo, los valores reportados varían según el fluoróforo de $\mathrm{Ca}^{2+}$ utilizado, la técnica de calibración y si se utilizan músculos de anfibio o mamífero (31-36). Una vez liberado, el $\mathrm{Ca}^{2+}$ se difunde en milisegundos, llegando a interactuar con la troponina C $(31,37)$. $\mathrm{La}$ interacción del $\mathrm{Ca}^{2+}$ con la troponina $\mathrm{C}$ suspende la inhibición que la troponina I y la tropomiosina ejercen sobre la interacción actinamiosina, lo que permite el deslizamiento de los filamentos delgados sobre los gruesos y genera tensión (37).

La tasa de remoción de $\mathrm{Ca}^{2+}$ citoplásmico es, aproximadamente, de $50 \mu$ moles $/ \mathrm{ms}$ y es amortiguado inicialmente por proteínas solubles citoplásmicas como la parvalbúmina $\mathrm{y}$, finalmente, recapturado por la ATPasa de $\mathrm{Ca}^{2+}$ 
del retículo sarcoplásmico (sarco-endoplasmic reticulum calcium ATPase, SERCA) (7). Mientras que las proteínas citosólicas tamponan el $\mathrm{Ca}^{2+}$ de manera transitoria con una cinética rápida, la SERCA retorna el $\mathrm{Ca}^{2+}$ a su interior con una cinética más lenta. La parvalbúmina es una proteína monomérica de $12 \mathrm{kDa}$, que une $\mathrm{Ca}^{2+} \mathrm{y}$ $\mathrm{Mg}^{2+}$ con alta afinidad y tiene un papel importante en la relajación de los músculos rápidos (38).

La SERCA es una proteína de 110 kDa ubicada básicamente en la región longitudinal del retículo sarcoplásmico; la regulación de su expresión y función es bastante compleja, e incluye el $\mathrm{Ca}^{2+}$, el $\mathrm{pH}$, las hormonas tiroideas y las proteínas fosfolambán y sarcolipina $(7,39-44)$. La proteína tiene tres grandes dominios citoplásmicos unidos a un dominio que consta de 10 hélices hidrofóbicas que atraviesan la membrana del retículo sarcoplásmico. Grandes movimientos, principalmente de los dominios citoplásmicos, median el paso del $\mathrm{Ca}^{2+}$ del citoplasma al interior del retículo sarcoplásmico en contra de su gradiente de concentración (45), lo cual disminuye los niveles de $\mathrm{Ca}^{2+}$ citoplásmicos a valores en el orden nanomolar en milisegundos (7), asegurando así una rápida relajación del músculo esquelético. De esta forma, el músculo se encuentra listo para responder ante un nuevo estímulo.

La descripción anterior hace un breve recorrido por gran parte del conocimiento que se ha acumulado sobre el acoplamiento excitacióncontracción en el músculo esquelético en las últimascinco décadas, utilizando una combinación de aproximaciones experimentales, varias de las cuales serán discutidas a continuación.

\section{Técnicas de estudio del mecanismo de acoplamiento excitación-contracción}

\section{Algunos trabajos experimentales clásicos}

Son clásicos los trabajos de Sandow en la década del 50, quien utilizó electrodos para registrar los potenciales de acción y transductores para registrar la tensión generada por la fibra muscular activada $(1,2)$. Paralelamente, FranziniArmstrong y Porter estudiaron la tríada y el retículo sarcoplásmico mediante microscopía electrónica
(16). Más tarde, otros autores como Weber, Hasselbach, Endo y Ebashi (5-9), mediante técnicas bioquímicas, permitieron reconocer la importancia del $\mathrm{Ca}^{2+}$ en el acoplamiento excitación-contracción.

En las últimas dos décadas el uso de técnicas de biología molecular ha permitido obtener las secuencias de las proteínas involucradas (receptores de rianodina, receptores de dihidropiridinas y la SERCA) $(22,46)$, así como evaluar las modificaciones inducidas en ellas, por ejemplo, por oxidación o fosforilación (47). Además, el uso de indicadores fluorescentes de $\mathrm{Ca}^{2+}$ y de una gran variedad de sustancias (agonistas o antagonistas), como la cafeína, la rianodina, los nitratos, el cinc y los inhibidores de la SERCA, ha permitido obtener valiosa información acerca de la cinética del $\mathrm{Ca}^{2+}$ en el fenómeno de acoplamiento excitacióncontracción.

\section{Preparaciones celulares utilizadas para el estudio del acoplamiento excitación- contracción}

\section{Disociación enzimática y aislamiento manual}

Se pueden obtener fibras musculares intactas para experimentación mediante disociación enzimática o por aislamiento manual. En el primer caso, se utiliza la técnica descrita por Bekoff y Betz (48) y modificada por Caputo y colaboradores (32, Calderón-Vélez J, Bolaños $P$, Caputo $\mathrm{C}$. Functional identification of fiber types in enzimatically dissociated murine flexor digitorum brevis (FDB) and soleus muscles. Biophys J. 2009;96(3-S1):233a). En esta técnica se utilizan diferentes músculos, como el flexor digitorum brevis o el soleus de ratones o ratas, los cuales se someten a una disociación enzimática con colagenasa, para separar las fibras del tejido conjuntivo circundante $y$, posteriormente, a una disociación mecánica con el uso de pipetas pulidas de distintos diámetros, para así obtener finalmente fibras musculares enteras libres de su tendón. El aislamiento manual apela a la habilidad del investigador para disecar un músculo y obtener fascículos de pocas fibras, usualmente 5 a 20, u obtener una fibra aislada adherida a sus respectivos tendones. Se verifica 
la integridad de la fibra visualmente, observando la respuesta a un estímulo eléctrico (49).

\section{Fibras desnudas mecánica y químicamente}

Estas técnicas permiten acceder directamente al interior de la fibra muscular, pues en ambas se remueve mecánicamente el sarcolema (por microdisección) o con glicerol o detergentes suaves (50). Según la intensidad del tratamiento, se puede respetar la función del retículo sarcoplásmico. Se ha demostrado que, en las fibras desnudadas mecánicamente, los túbulos $\mathrm{T}$ se resellan quedando como un compartimiento separado y cerrado, mientras que el compartimiento mioplásmico queda abierto a la manipulación experimental (véanse ejemplos en la referencias 51 y 52). Así, se puede determinar, por ejemplo, el efecto del cambio de $\mathrm{pH}$ o del cambio de concentración de algún metabolito, como fosfato o lactato, sobre la sensibilidad de las miofibrillas al $\mathrm{Ca}^{2+}$ y la fuerza máxima generada con máximo $\mathrm{Ca}^{2+}$ citosólico. Tiene la desventaja de remover, además de las membranas, compuestos citosólicos como el glutatión, el ATP y la parvalbúmina, lo cual puede dificultar la interpretación de algunos resultados.

\section{Cultivos celulares}

Los cultivos primarios y las líneas celulares comerciales bien establecidas, como $\mathrm{C} 2 \mathrm{C} 12$ y L6, mioblastos provenientes de ratón y rata, respectivamente $(53,54)$, poseen un elevado potencial de diferenciación que les confiere características idóneas para estudios de desarrollo in vitro, diferenciación y señalización, tanto a nivel funcional como bioquímico y molecular. En ambos casos, los cultivos se mantienen en un medio de crecimiento hasta alcanzar $\sim 60 \%$ de confluencia para luego inducir la diferenciación (formación de miotubos), disminuyendo la cantidad de suero en el medio de cultivo. Debido principalmente a las características estructurales que alcanzan los miotubos en cultivo, los resultados funcionales están limitados a comparaciones in vivo con etapas de desarrollo muy tempranas; algunos de los hallazgos con este modelo experimental no se han podido reproducir en modelos in vivo de fibras neonatales.

\section{Procedimientos experimentales}

Mediciones de transitorios de $\mathrm{Ca}^{2+}$

Hace poco más de cuatro décadas, Ridgway y Ashley (55) pudieron registrar por primera vez los movimientos transitorios de $\mathrm{Ca}^{2+}$, globales o macroscópicos, dentro de fibras musculares estimuladas eléctricamente. Los autores utilizaron la fotoproteína aequorina, la cual emite luz en presencia de $\mathrm{Ca}^{2+}$ a diferencia de muchas otras moléculas, posteriormente sintetizadas, que tienen la propiedad de cambiar su intensidad de fluorescencia o la longitud de onda a la cual emiten o absorben luz cuando unen el ion $\mathrm{Ca}^{2+}$, representando así una herramienta invaluable para registrar cambios en la concentración intracelular de $\mathrm{Ca}^{2+}$ luego de diversos estímulos (56-59).

Por lo general, los registros de transitorios de $\mathrm{Ca}^{2+}$ obtenidos con estas moléculas fluorescentes presentan las siguientes características cinéticas: i) una fase de ascenso, que refleja la salida de $\mathrm{Ca}^{2+}$ del retículo sarcoplásmico y su presencia, en forma libre, en el citoplasma, ii) un pico (o máximo), cuando se detiene la salida de $\mathrm{Ca}^{2+,}$ y iii) una fase de caída, que representa la activación de los mecanismos de remoción del $\mathrm{Ca}^{2+}$ libre en el citoplasma.

Se pueden medir movimientos transitorios de $\mathrm{Ca}^{2+}$ en fibras disociadas enzimáticamente, disecadas manualmente y en miotubos. Para ello se utilizan indicadores fluorescentes (fluoróforos) acoplados a un grupo acetoxi-metiléster que permite su paso al interior celular; una vez en el citoplasma, este grupo es separado por las esterasas celulares, quedando la molécula del fluoróforo en forma activa, es decir, con capacidad de unir $\mathrm{Ca}^{2+}$ y emitir luz (60). Entre los compuestos de este tipo más comúnmente utilizados encontramos: Fura2-AM, Indo1, MagFura2-AM, Fluo3-AM, Fluo4-AM y MagFluo4AM. Las diferencias entre los indicadores radican principalmente en sus espectros de excitación y emisión, y en la constante de disociación para el $\mathrm{Ca}^{2+}\left(\mathrm{K}_{\mathrm{d}}\right)$, por lo que la cinética de los transitorios, tanto durante la fase de ascenso como durante la de caída, depende del fluoróforo utilizado (figura 1). 
La cinética de los movimientos transitorios $\mathrm{de}^{\mathrm{Ca}^{2+}}$ obtenida con algunos indicadores fluorescentes se ha corregido frente a otros, considerados mejores. Sin embargo, aún permanece sin aclararse el valor absoluto, por ejemplo, de la tasa de liberación de $\mathrm{Ca}^{2+}$ desde el retículo sarcoplásmico (ver arriba).

\section{Mediciones de tensión}

Para las mediciones de tensión se utilizan fascículos de pocas fibras y fibras aisladas manualmente, tanto de músculos rápidos como lentos, de anfibio y de mamífero. De esta forma, las fibras musculares permanecen unidas a sus tendones. Las fibras aisladas o los fascículos se montan horizontalmente en la cámara experimental y se fijan, con la ayuda de pequeños clips de aluminio, por un extremo a un transductor de tensión y por el otro a un gancho fijo a la cámara. Las contracciones se producen por estimulación de campo supraumbral mediante electrodos que corren paralelamente a lo largo de la cámara (49) (figura 2). Es posible obtener mediciones simultáneas de $\mathrm{Ca}^{2+}$ y tensión (figura 2). Esto permite calcular, por ejemplo, la sensibilidad de las miofibrillas al $\mathrm{Ca}^{2+}$ en fibras
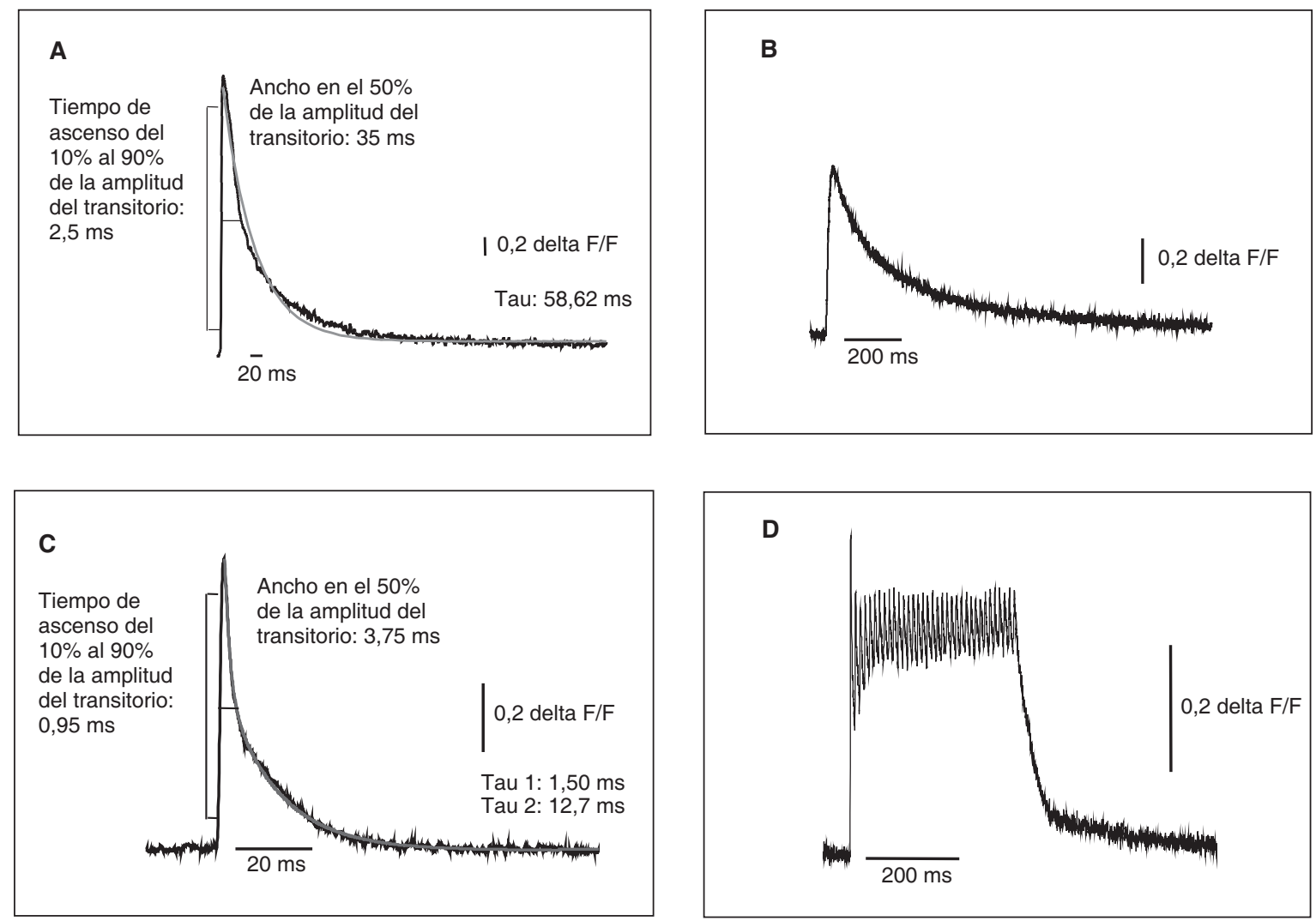

Figura 1. A. Cinética de un transitorio de calcio de una sacudida simple, representativo de las fibras del flexor digitorum brevis (FDB) de ratón adulto, obtenido con el indicador Fluo4-AM. La línea gris representa el ajuste realizado en la fase de caída con una exponencial simple (Tau). Se muestran los valores de los parámetros cinéticos característicos del transitorio.

B. Transitorio de calcio registrado en un miotubo proveniente de un cultivo primario 4 días después de inducir la diferenciación; obtenido con Fluo4-AM. C. Cinética de un transitorio de calcio de una sacudida simple, representativo de las fibras del FDB de ratón adulto, obtenido con el indicador MagFluo4-AM. La línea gris representa el ajuste realizado con dos exponenciales (Tau 1, Tau 2). Se muestran los valores de los parámetros cinéticos característicos del transitorio. D. Transitorio de calcio representativo de un tétanos de $350 \mathrm{~ms}$ de duración a una frecuencia de $100 \mathrm{~Hz}$, en fibras de FDB, obtenido con MagFluo4AM. La amplitud de los registros es expresada como la variación de la fluorescencia inducida por el estímulo en comparación con la fluorescencia en reposo (delta F/F). 
intactas o seguir los cambios de ambas variables durante la fatiga muscular.

\section{Electrofisiología}

Las mediciones de corrientes iónicas de membrana $\left(\mathrm{Na}^{+}, \mathrm{K}^{+}\right.$y $\mathrm{Ca}^{2+}$, principalmente) y de movimientos de carga intramembrana, mediante el control del voltaje de membrana, son de gran interés para el estudio de numerosos aspectos de la fisiología y fisiopatología del músculo esquelético. Usualmente, para registros en miotubos y fibras aisladas enzimáticamente se emplea el whole-cell voltage clamp de dos o tres electrodos, el cual permite obtener registros de corrientes iónicas totales. Sin embargo, en fibras adultas y debido a su gran longitud, es necesario aislar zonas de la fibra aplicando grasa o silicona (vaseline-gap isolation and siliconeclamp technique), para así poder hacer registros de corrientes totales sólo en las regiones no aisladas del medio extracelular (61).

En los registros obtenidos se analiza principalmente la amplitud de la corriente y su dependencia del voltaje. Las despolarizaciones se producen desde un voltaje predeterminado (holding potential), el cual usualmente se fija entre $-80 \mathrm{y}$
$-100 \mathrm{mV}$, hasta un voltaje variable; usualmente se obtienen registros con despolarizaciones entre -80 y $-10,0,+10$ y $+30 \mathrm{mV}$ (62).

\section{Microscopía confocal de barrido láser}

La microscopía confocal de barrido láser y, más recientemente, la microscopía multifotónica, han permitido realizar análisis precisos temporales y espaciales de los movimientos de $\mathrm{Ca}^{2+}$ a nivel subcelular. Las fibras y miotubos pueden ser cargados con indicadores como di-8-ANEPPS para marcar el sarcolema y los túbulos T; Rhod-2 y Fluo4-AM para el $\mathrm{Ca}^{2+}$ citoplásmico; ERTG (endoplasmic reticulum-tracker green) para el retículo sarcoplásmico y Mitotracker Green-FM y CalciumOrange-5N para las mitocondrias.

La microscopía confocal tiene las siguientes ventajas en comparación con la microscopía óptica: i) presenta mayor resolución y mejor contraste, permite obtener mejor información estructural (por ejemplo, túbulos $\mathrm{T}$, retículo sarcoplásmico o mitocondria) y funcional (se registran eventos de interés como movimientos de $\mathrm{Ca}^{2+}$ o cambios de potencial de membrana); ii) permite obtener imágenes para su posterior análisis (cambios temporales, medidas de
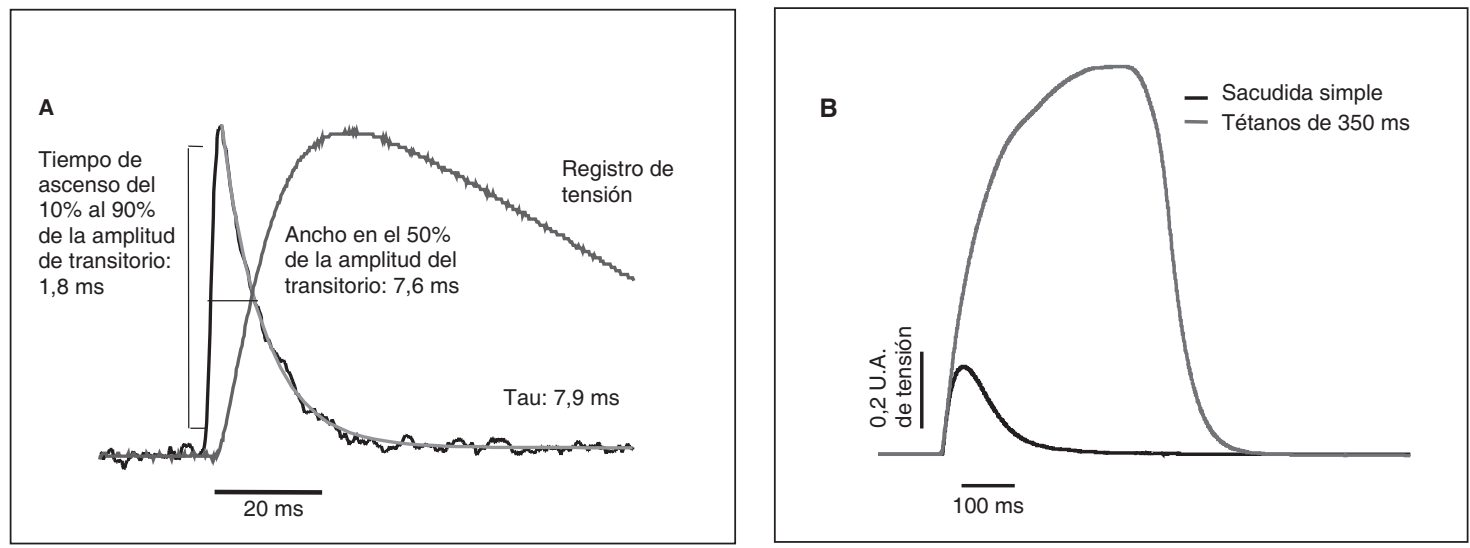

Figura 2. A. Registro simultáneo de calcio (línea negra) y tensión (línea gris oscuro) de una sacudida simple de una fibra de anfibio aislada manualmente y cargada con el indicador fluorescente MagFluo4-AM. La línea gris claro representa el ajuste realizado en la fase de caída, del transitorio de calcio, con una exponencial simple (Tau). Se muestran los valores de los parámetros cinéticos característicos del transitorio. Las señales están normalizadas. B. Registro de tensión de una sacudida simple y un tétanos de $350 \mathrm{~ms}$ de duración a una frecuencia de $100 \mathrm{~Hz}$, obtenidos de un fascículo de aproximadamente15 fibras de flexor digitorum brevis de ratón adulto disecado manualmente. La tensión desarrollada durante el tétanos es aproximadamente 4 veces más grande que la desarrollada durante la sacudida simple. U.A.: unidades arbitrarias. (A, cortesía de Pura Bolaños). 
intensidad de fluorescencia y morfométricas entre otras); iii) permite el registro simultáneo de varias estructuras o eventos y su posterior análisis conjunto (véase un ejemplo en la referencia 63); iv) da la posibilidad de realizar secciones ópticas, lo cual es especialmente importante cuando se pretende determinar la localización de compuestos fluorescentes, y hacer reconstrucciones tridimensionales además de obtener imágenes multidimensionales en función del tiempo.

La aplicación de la microscopía confocal de barrido láser ha permitido registrar y caracterizar señales microscópicas fluorescentes de $\mathrm{Ca}^{2+}$ muy localizadas, denominadas sparks, inicialmente descritas en músculo cardíaco y sugeridas como eventos discretos de liberación de $\mathrm{Ca}^{2+}$ generados por la apertura de uno o pocos receptores de rianodina (64). En el caso del músculo esquelético, se han podido identificar sparks en anfibios, en embriones de mamífero y en miotubos en cultivo (65). Además, el empleo de la microscopía confocal de barrido láser en combinación con novedosas técnicas como la transferencia de energía por resonancia de fluorescencia (FRET) y la relación del desplazamiento del espectro de emisión/excitación (SEER) han permitido, entre otros hallazgos, estudiar el acoplamiento entre los receptores de dihidropiridinas y los de rianodina, y lograr imágenes confocales que permiten cuantificar el $\mathrm{Ca}^{2+}$ dentro del retículo sarcoplásmico, respectivamente $(66,67)$.

\section{Otros procedimientos}

i) La microscopía electrónica (estándar, sombreado metálico, criomicroscopía y reconstrucciones tridimensionales) ha producido importante información sobre la estructura de la tríada, de los sistemas de membranas (túbulos $\mathrm{T}$ y retículo sarcoplásmico) e incluso sobre los receptores de dihidropiridinas y los de rianodina. Debido a que no se cuenta con una imagen proveniente de la difracción de rayos $X$, por las dificultades para cristalizar las proteínas (receptores de dihidropiridinas y los de rianodina), se ha utilizado la criomicroscopía de las partículas aisladas y las reconstrucciones tridimensionales para la caracterización funcional y estructural; sin embargo, la resolución que se obtiene no permite una clara asignación de una estructura secundaria en forma no ambigua (ver adelante) (68).

ii) Diversas técnicas de biología molecular e ingeniería genética han aportado valiosa información sobre el músculo esquelético en condiciones normales y patológicas, ya que han permitido la evaluación funcional de la expresión (o ausencia) de proteínas involucradas en el acoplamiento excitación-contracción, por ejemplo: a) ratones knock out para algunas proteínas, entre ellos ratones disgénicos, carentes de la subunidad $\alpha-1$ de los receptores de dihidropiridinas, y ratones dispédicos, carentes de receptores de rianodina 1 (véase un ejemplo en las referencias 29 y 62); (b) silenciamiento de genes como el gen que codifica para la proteína integral del retículo sarcoplásmico, JP-45, demostrando su importancia para la expresión funcional de los receptores de dihidropiridinas (69); c) la producción y extracción de proteínas recombinantes con un alto rendimiento cualitativo y cuantitativo en fibras esqueléticas de mamífero adulto (70), lo cual ha permitido evaluar el efecto de la expresión de canales iónicos mutados y de la expresión exagerada de proteínas endógenas, como CSQ1, sobre el acoplamiento excitacióncontracción en fibras adultas (Royer L, Pouvreau S, Wang Y, Meissner G, Zhou J, Volpe P, et al. Functional and structural consequences of transiently increasing calsequestrin concentration by $\sim 700 \%$ in mouse skeletal muscle. Biophys J. 2008a:99-100a).

\section{Preguntas por responder}

\section{Estructura y acoplamiento receptor de dihidropiridinas-receptor de rianodina}

Los receptores de dihidropiridinas son heteropentámeros formados por las subunidades $\alpha_{1}$, $\alpha_{2}, \beta, \gamma$ y $\delta$, se encuentran dispuestos en tétradas e interactúan con los receptores de rianodina $(10,23,71)$. La función de los receptores de dihidropiridinas en el acoplamiento excitacióncontracción y como canales de $\mathrm{Ca}^{2+}$ tipo $\mathrm{L}$ está regulada por el potencial de membrana; los dominios transmembrana S4 de la subunidad $\alpha_{1}$ constituyen probablemente el sensor de 
voltaje, responsable de generar un cambio en la conformación, aún no completamente aclarado, que finalmente lleva a la apertura del receptores de rianodina (17-21). La interacción entre los receptores de dihidropiridinas y los de rianodina llevaría a la apertura o cierre de los receptores de rianodina de manera cooperativa (72).

El receptor de rianodina es un homotetrámero de alto peso molecular, cuya forma clásicamente se ha asociado a la de un champiñón: una gran masa que sobresale en el citoplasma y que tiene los sitios de regulación, y un tallo que atraviesa la membrana del retículo sarcoplásmico $(21,22,68,73)$.

Parece claro que hay un acoplamiento mecánico y bidireccional de la conformación entre el receptor de dihidropiridinas y el de rianodina en el músculo esquelético (74-76), el cual estaría mediado por las asas internas que unen los dominios transmembrana II y III del receptor de dihidropiridinas y una región corta específica del de rianodina (77-79), aunque algunos estudios sugieren que son múltiples las regiones de receptores de rianodina 1 que interactúan con el receptor de dihidropiridinas (80) y múltiples las subunidades del receptor de dihidropiridinas que lo hacen con el de rianodina 1 (66).

Los estudios sobre la interacción entre estos dos receptores se han basado en su mayoría en mutaciones sitio-dirigidas de aminoácidos localizados en dominios específicos; sin embargo, los movimientos de los diferentes dominios involucrados en dicha interacción no se han aclarado por completo, debido a la falta de información procedente de estudios de cristalografía o de resonancia magnética de ambos canales bajo diferentes condiciones, principalmente, por el obstáculo que ofrece el gran tamaño de las dos proteínas. Aunque la estructura tridimensional del asa II-III aislada del receptor de dihidropiridinas ya se conoce $(47,79)$, no se sabe si ésta adopta una estructura diferente cuando se une al receptor de rianodina o si la estructura determinada es fiel a la presente en la molécula completa.

Hasta ahora la información estructural sobre el receptor de dihidropiridinas y el de rianodina proviene básicamente de estudios de criomicroscopía y reconstrucción tridimensional (68, $73,81,82)$. Aunque varios grupos trabajan para resolver la estructura terciaria de ambas proteínas $(81,82)$, apenas recientemente se consiguió una resolución subnanométrica (9,6 A para el receptor de rianodina) (81). Los autores han puesto particular énfasis en la estructura del poro del receptor de rianodina en su estado cerrado. Ludtke y colaboradores (81) identificaron 5 hélices $\alpha$ por monómero en la región transmembrana y sugirieron que las hélices 1 de cada subunidad forman el poro y las hélices 2 el filtro de selectividad. Samsó y colaboradores (82) sugirieron la existencia de al menos 6 hélices transmembrana por monómero y describieron con algún detalle las estructuras conocidas como columnas, que unen la porción transmembrana con el gran dominio citosólico. Es posible que la estructura del poro tenga similitudes con estructuras de canales de $\mathrm{K}^{+}$ya publicadas $(83,84)$; sin embargo, los autores no se ponen de acuerdo sobre si dicha similitud es con el canal MthK o con el KcsA $(81,82)$.

La resolución máxima obtenida $(9,6 \AA$ para el receptor de rianodina 1 y $30 \AA$ para el de dihidropiridinas) no es suficiente para dar detalles como: i) presencia, distribución y movimiento de hélices $\alpha$ y láminas $\beta$, que expliquen, por ejemplo, cómo se transmite la señal desde el receptor de dihidropiridinas al de rianodina y la información de los reguladores de éste último desde algún punto de la proteína al poro para permitir la salida de $\mathrm{Ca}^{2+}$; ii) delimitación de las diferentes subunidades en cada una de las proteínas; iii) el mecanismo molecular preciso de interacción entre los receptores; iv) cuántas hélices del receptores de rianodina atraviesan la membrana del retículo sarcoplásmico, el número propuesto de hélices transmembrana ha variado entre 4 (22) y 10-12 (85).

La respuesta a éste y a los demás interrogantes sobre el receptor de rianodina no se dará hasta que se obtenga una imagen de la estructura del canal de al menos 4-6 Å de resolución.

Las imágenes de las proteínas aisladas no necesariamente reflejan la estructura de complejos 
como el de la tríada. Recientemente se obtuvieron imágenes utilizando criomicroscopía, tomografía electrónica y técnicas de reconstrucción tridimensional, de tríadas aisladas de conejo (75) con una resolución aproximada de $6 \mathrm{~nm}$.

Esteestudioconfirmaalgunoshallazgosobtenidos previamente por otros autores $(16,23,24)$ y llama la atención sobre la existencia de algunas características estructurales nuevas: i) habría una estructura de unos $5 \mathrm{~nm}$ de ancho que subyace a la membrana interna del retículo sarcoplásmico, de naturaleza desconocida; ii) las partículas de calsequestrina parecen estar interconectadas entre sí dentro del retículo sarcoplásmico; iii) en la luz de las vesículas de túbulos $T$ parecerían existir estructuras de naturaleza molecular desconocida que podrían tener un papel estructural; iv) se observa la presencia de estructuras que cubren las distancias entre la región citoplásmica del receptor de rianodina y el túbulo $T$, las cuales no pueden asignarse a un dominio proteico claro, pero podrían ser asas del receptor de dihidropiridinas. A pesar de las ventajas de esta técnica, los resultados presentados podrían afectarse por la inducción de artefactos durante el procesamiento de la muestra y por la baja resolución de las imágenes obtenidas.

Al margen de lo anterior, sobre la tríada aún no se conoce con certeza: i) la distancia exacta entre las membranas del retículo sarcoplásmico y del túbulo $T$ (la cual parece estar entre 10 y $20 \mathrm{~nm}$ ), así como la que existe entre el dominio citoplásmico del receptor de rianodina y la membrana del túbulo $T$; ii) el mecanismo exacto de la interacción funcional y estructural directa entre el receptor de rianodina y el de dihidropiridinas (movimientos y sitios de interacción entre las dos proteínas); iii) la organización tridimensional del complejo de la tríada incluyendo a las proteínas ya identificadas molecularmente (calsecuestrina, triadina, junctina, SRP-27) y otras aún no identificadas, como las sugeridas por el estudio discutido arriba (véase un modelo propuesto en las referencias 47 y 75 ); iv) la forma en que interactúan las proteínas en el complejo de la tríada (además de las interacciones entre receptores ya discutidas) y cuál es la implicación funcional de estas interacciones; se debe llegar a conocer cuáles aminoácidos están involucrados en las interacciones intraproteicas e interproteicas.

\section{Mecanismo de acoplamiento excitación- contracción y fatiga muscular}

La fatiga muscular se define como la dificultad para mantener el rendimiento o trabajo muscular en términos de potencia (fuerza y velocidad), esperado o requerido (86-88).

La falla que impide mantener la fuerza requerida se podría presentar, en teoría, en cualquiera de los eventos o estructuras a lo largo de la vía entre el sistema nervioso central y la maquinaria contráctil de las fibras musculares $(10,86,89)$.

El mecanismo fisiológico que explica el fenómeno de la fatiga del músculo esquelético no está claro y el tema se sigue considerando controversial; se han propuesto varias hipótesis para explicarlo $(86-88,90)$, la mayoría relacionadas con alteraciones del mecanismo de acoplamiento excitación-contracción.

\section{Mecanismos central y periférico de la fatiga muscular}

La fatiga de origen central involucra los eventos que se dan antes del fenómeno de acoplamiento excitación-contracción y la fatiga de origen periférico involucra los eventos que incluyen el acoplamiento excitación-contracción y los demás que suceden dentro de la fibra muscular como consecuencia de su activación.

Es probable que la fatiga de origen central no sea el principal mecanismo de fatiga muscular $(86,89)$; según Kent-Braun (91), contribuye a explicar solamente el $20 \%$ de la fatiga muscular. Sin embargo, dicho componente central puede servir como modulador del fenómeno, sobre todo para proteger al músculo de las consecuencias de la fatiga extrema.

Está demostrado que la caída del potencial de acción no es la causa de la fatiga (92-94), tampoco el agotamiento del ATP o de las reservas energéticas $(92,95)$, aunque se ha planteado que una caída localizada de ATP cercana a puntos críticos podría ser importante (88). En lo 
que respecta a la alteración del fenómeno del acoplamiento excitación-contracción, la investigación se ha centrado en los fenómenos de regulación de la liberación y recaptura de $\mathrm{Ca}^{2+}$ (52).

Esta idea es apoyada principalmente por la observación de que, después de la fatiga, se puede reactivar el desarrollo de tensión por la adición de cafeína (93), un compuesto que favorece la salida de $\mathrm{Ca}^{2+}$ del retículo sarcoplásmico. Posteriormente, se demostró que las fibras fatigadas tienen transitorios tetánicos disminuidos (96, Calderón y Caputo, 2008, resultados sin publicarse).

La fatiga del mecanismo de liberación y recaptura de $\mathrm{Ca}^{2+}$ por el retículo sarcoplásmico $(52,86,97)$ podría ser mediada por alteraciones metabólicas intracelulares (3), entre las cuales son importantes las alteraciones del $\mathrm{pH}$, lactato, $\mathrm{Mg}^{2+}, \mathrm{Ca}^{2+}, \mathrm{Pi}, \mathrm{y}$ radicales libres, y especies reactivas de oxígeno.

Desde el trabajo clásico de Hill y Kupalov (98), la acumulación de lactato ha sido uno de los factores más propuestos para explicar la disminución del rendimiento muscular; sin embargo, su papel, así como el de la acidosis, aún es controversial (99-102).

En varios trabajos se ha reportado una disminución del pH (a valores, incluso, menores de 6,5$)$ y un aumento del lactato que se han relacionado con la fatiga (91,103-105).

El efecto del pH sobre el mecanismo de acoplamiento excitación-contracción parece tener que ver con la disminución de la potencia máxima de la fibra y con que a mayor acidosis se requiere mayor concentración de $\mathrm{Ca}^{2+}$ para alcanzar una tensión determinada $(86,106)$. Además, disminuye la capacidad del retículo sarcoplásmico para liberar $\mathrm{Ca}^{2+}(52,107)$.

Otro posible mecanismo que involucre el acoplamiento excitación-contracción como sitio potencial de la fatiga sería que un elevado $\mathrm{Ca}^{2+}$ basal intracelular $\left(\mathrm{Ca}^{2+}\right)$ desacople la interacción entre el receptor de dihidropiridinas y el de rianodina (52). Se ha encontrado aumento del $\mathrm{Ca}^{2+}{ }_{\mathrm{i}}$ durante el desarrollo de la fatiga $(96,108)$ y este aumento parece asociarse a alteración por parte de la fibra para generar tensión a pesar de que la capacidad del retículo sarcoplásmico para captar y liberar $\mathrm{Ca}^{2+}$ no se altera $(51,109)$.

La alteración de la función de la SERCA podría explicar el aumento persistente de $\mathrm{Ca}^{2+}{ }_{\text {i }}$ que lleva a la disrupción del acoplamiento excitacióncontracción y, posteriormente, a disminución de la liberación de $\mathrm{Ca}^{2+}$ con cada estímulo. En la fatiga se ha observado alteración de la captación máxima de $\mathrm{Ca}^{2+}$ por el retículo sarcoplásmico $(97,110,111)$. El trabajo reciente de Verburg y colaboradores (112), sin embargo, sugiere que no es el aumento del $\mathrm{Ca}^{2+}{ }_{i}$ basal, sino el aumento localizado del $\mathrm{Ca}^{2+}$ cerca a la tríada asociado a cada tétanos, el factor más importante para que se produzca el desacoplamiento.

El aumento del $\mathrm{Mg}^{2+}$, que se observa con la estimulación repetida (113) se ha relacionado con fatiga muscular. $\mathrm{El} \mathrm{Mg}^{2+}$, es un inhibidor fisiológico de la liberación de $\mathrm{Ca}^{2+}$ desde el retículo sarcoplásmico $(10,25)$. Sin embargo, de algunos trabajos $(113,114)$ se concluye que, aunque el $\mathrm{Mg}^{2+}$ puede ser un factor que favorece el desarrollo de fatiga, para que su efecto sea importante se necesitan concentraciones muy altas, las cuales no se alcanzan en una fibra muscular fatigada.

También se ha encontrado aumento del fosfato $\left(P_{i}\right)$ libre durante el desarrollo de la fatiga y esto parece favorecer el depósito de $\mathrm{Ca}^{2+}$ dentro del retículo sarcoplásmico en la forma de fosfato de $\mathrm{Ca}^{2+}$, lo cual disminuye el $\mathrm{Ca}^{2+}$ disponible para ser liberado $(115,116)$. Además, el aumento de $P_{i}$ causa disminución de la sensibilidad del mecanismo contráctil al $\mathrm{Ca}^{2+}$ para generar tensión $(86,100)$.

Las alteraciones del estado de oxido-reducción asociadas a la actividad muscular parecen tener algún papel en el desarrollo de la fatiga muscular y en la alteración del acoplamiento excitacióncontracción (117-120, Calderón \& Caputo, 2008, resultados sin publicarse). Durante el ejercicio, el músculo y el organismo en general se ven sometidos a un gran estrés oxidativo, es decir, hay una pérdida del equilibrio entre la producción de radicales libres y especies reactivas de oxígeno, 
y la capacidad de las células para manejarlos (121-124). El aumento de los radicales libres parece alterar la liberación de $\mathrm{Ca}^{2+}$ desde el retículo sarcoplásmico, aunque el efecto sobre la fatiga muscular no está claro (125-127), además de disminuir la sensibilidad de la miofibrilla al $\mathrm{Ca}^{2+}$ en mamíferos $(128,129)$. Se han obtenido resultados contradictorios en cuanto al efecto de los radicales sobre la fuerza máxima de la fibra muscular y sobre el Ca ${ }^{2+}$ tetánico (128,139-133).

Aún no está claro cuál es el papel de los radicales libres y las especies reactivas de oxígeno en la fatiga; tampoco está claro qué papel juega la peroxidación lipídica en la alteración de las diferentes bombas que se observan modificadas en la fatiga. Algunos resultados del laboratorio de fisiología celular del Instituto Venezolano de Investigaciones Científicas, utilizando fascículos aislados manualmente de flexor digitorum brevis de ratón, sugieren que las especies reactivas de oxígeno podrían tener un importante papel en la fatiga muscular (Calderón \& Caputo, 2008, resultados sin publicarse). Aún así, no se sabe cuáles especies químicas están implicadas y cuáles son los blancos modificados que median los fenómenos de fatiga.

En conclusión, el fenómeno de fatiga muscular es bastante complejo y parece ser multicausal. Sin embargo, la mayoría de los fenómenos observados parecen alterar el mecanismo de acoplamiento excitación-contracción. Aunque se ha sugerido que alteraciones del $\mathrm{pH}$, lactato, ATP, $\mathrm{Mg}^{2+}, \mathrm{Ca}^{2+}, \mathrm{P}_{i}$ y especies reactivas de oxígeno mediarían este fenómeno, parece poco probable que las alteraciones del ATP y $\mathrm{Mg}^{2+}$ estén involucradas; de la misma forma, las alteraciones del $\mathrm{pH}$ y del lactato, aunque importantes, no parecen ser el principal mecanismo de fatiga muscular.

Cómosemodificanlosfactoresarribamencionados durante la fatiga de fibras en desarrollo o en la vejez es desconocido. Igualmente, falta por aclarar el papel de múltiples reguladores del acoplamiento excitación-contracción, como la proteína S100A1, el fosfolambán, la sarcolipina y las proteínas del complejo de la tríada, etc., en la fatiga muscular.

\section{Acoplamiento excitación-contracción en desarrollo en neonatos}

Las fibras musculares esqueléticas de roedores y de otros mamíferos están incompletamente diferenciadas al nacer. Durante las primeras semanas posnatales ocurren varios cambios fisiológicos, bioquímicos y morfológicos, antes de que los músculos alcancen propiedades adultas características. Por ejemplo, en ratas y ratones la diferenciación en fibras de contracción rápida y lenta, los cambios progresivos en las actividades enzimáticas musculares, el desarrollo del sistema de túbulos $\mathrm{T}$, la reorganización del patrón de inervación polineural o focal y la maduración de la unión neuromuscular, entre otros eventos, ocurren durante el primer mes después de nacer (134).

Siguiendo la secuencia de eventos que ocurren durante el acoplamiento excitación-contracción en fibras musculares adultas de vertebrados, tenemos que, durante el desarrollo posnatal de músculo esquelético de ratones, ocurren principalmente las siguientes modificaciones:

i) La desaparición de la inervación polineural entre los días 16 y 18 después del nacimiento (135).

ii) El potencial de membrana en reposo de fibras musculares esqueléticas durante el periodo posnatal se encuentra despolarizado con respecto a fibras adultas, $-41,8$ y $-76,4 \mathrm{mV}$ a los 4 y 27 días de edad, respectivamente (134).

La concentración intracelular de $\mathrm{K}^{+}$se incrementa (83 y $117 \mathrm{mM}$ a los 8 y 29 días) mientras que la concentración intracelular de $\mathrm{Na}^{+}$disminuye (24 y $10 \mathrm{mM}$ a los 8 y 27 días). Existen evidencias, en músculo esquelético de ratas, de la existencia de un incremento de los sitios de unión a ouabaína a partir del segundo día luego del nacimiento hasta los 28 días de edad, lo cual indica un aumento en la expresión de la $\mathrm{Na}^{+} / \mathrm{K}^{+}$ATPasa (136).

Después del nacimiento, la mayoría de las fibras musculares de rata presentan potenciales de acción que son insensibles a tetrodotoxina; la sensibilidad comienza a partir del décimo día después del nacimiento y es después de los 20 días de edad cuando la generación del potencial 
de acción es completamente bloqueada por tetrodotoxina (137). Los potenciales de acción de las fibras neonatales presentan una clara hiperpolarización después de la fase de descenso que no se observa en fibras adultas y, además, las amplitudes de los mismos en fibras adultas son, aproximadamente, $30 \%$ más grandes que en fibras jóvenes (138).

Los miotubos de músculo esquelético de vertebrados crecidos en cultivo muestran descargas de potenciales de acción espontáneas, producto de una corriente rápida de $\mathrm{Na}^{+}$sensible a tetrodotoxina, una corriente lenta despolarizante insensible a tetrodotoxina transportada tanto por $\mathrm{Na}^{+}$como por $\mathrm{Ca}^{2+}$, una corriente de $\mathrm{K}^{+}$ "rectificadora retardada" dependiente de $\mathrm{Ca}^{2+} \mathrm{y}$ una corriente lenta de $\mathrm{Cl}^{-}$(139).

iii) Al nacer, las fibras musculares esqueléticas de ratones presentan túbulos $\mathrm{T}$, predominantemente longitudinales, pero con numerosas conexiones transversales; 4 días después del nacimiento se observa un incremento notable en el número de tríadas en los sitios de unión entre las bandas A-I y ya a los 10 días de edad se alcanza una orientación transversal de los túbulos $T$ y de las tríadas; aunque no es sino hasta los 20 días después del nacimiento cuando se alcanza un sistema tubular completamente maduro (140).

Los canales de $\mathrm{Ca}^{2+}$ tipo $\mathrm{L}$ en miotubos se localizan en el sarcolema en etapas tempranas del desarrollo y luego migran hacia el sistema membranoso tubular $\mathrm{T}$ en etapas tardías; su expresión se incrementa y alcanza un máximo antes que los receptores de rianodina 1. Estos últimos requieren de 3 a 4 semanas para alcanzar su máxima expresión y luego se mantiene durante la etapa adulta.

Por el contrario, la isoforma 3 del receptor de rianodina alcanza un máximo de expresión el día 15 de la etapa posnatal y, posteriormente, desaparece a las 3-4 semanas (141). Además, durante el período posnatal se ha observado una expresión transitoria de la isoforma cardiaca de los receptores de dihidropiridinas (142).

Tanto in vivo como in vitro, durante el desarrollo del músculo esquelético, además de una corriente de entrada de $\mathrm{Ca}^{2+}$ dependiente de voltaje tipo $\mathrm{L}$, sensible a dihidropiridinas y que persiste hasta el estado adulto, existe una corriente rápida o transitoria (tipo T) activada a potenciales de membrana muy por debajo del umbral de contracción (próximos al potencial de membrana en reposo), insensible a dihidropiridinas y que desaparece entre la tercera y cuarta semanas luego del nacimiento (143-146).

El músculo esquelético en desarrollo presenta un componente de la contracción dependiente de $\mathrm{Ca}^{2+}$ externo $(138,147$, Figueroa LC, Bolaños $\mathrm{P}$, Caputo $\mathrm{C}$. $\mathrm{Ca}^{2+}$ signaling during development of muscle fibers and primary culture myotubes. Biophy J. 2007;311a) que desaparece paralelamente con la desaparición de la corriente tipo $T$ y con el incremento de la corriente tipo $L$ y del movimiento de carga (145). A medida que el miotubo madura, los receptores de dihidropiridinas funcionan preferencialmente para sensar voltaje más que para sustentar una entrada de $\mathrm{Ca}^{2+}$, ya que presentan una cinética lenta de activación en respuesta a una estimulación por voltaje (148).

iv) En la etapa posnatal de fibras musculares de rata, la transición de las isoformas de miosina de una forma neonatal a una forma adulta (149) y la expresión de patrones adultos de troponina (150) y de tropomiosina (151) coinciden con la aparición de la parvalbúmina, entre la tercera y cuarta semana después del nacimiento (152). Además, en el músculo esquelético de ratones la expresión de la SERCA es apenas detectable en ratones de dos a cinco días (141).

Recientes trabajos realizados en el Laboratorio de Fisiología Celular del Instituto Venezolano de Investigaciones Científicas se han enfocado en dilucidar cómo es el establecimiento gradual de los mecanismos del acoplamiento excitacióncontracción durante el desarrollo postnatal.

En relación con las características cinéticas de los transitorios de $\mathrm{Ca}^{2+}$, se ha encontrado una disminución progresiva de los tiempos de ascenso y de descenso a medida que aumenta la edad de la fibra (figura 3), debido, principalmente, a una composición diferencial de receptores de rianodina y a una mayor contribución de la 
SERCA en fibras neonatales en comparación con las adultas (138).

Además, se ha observado una contribución importante del $\mathrm{Ca}^{2+}$ extracelularenelacoplamiento excitación-contracción en fibras neonatales y de miotubos en cultivo $(138,153)$. Mediante comparaciones sistemáticas de estudios in vivo con estudios in vitro de fibras neonatales y fibras adultas, se ha observado en etapas tempranas de cultivo (menores de cinco días) un potencial de diferenciación disminuido en aquellos cultivos establecidos a partir de fibras adultas, lo cual se traduce en un retraso en la maduración de los mecanismos de acoplamiento excitacióncontracción con respecto a lo que sucede en miotubos provenientes de fibras neonatales; asimismo, resultados más recientes sugieren que los miotubos maduros (más de nueve días en cultivo) tienen mecanismos de remoción de $\mathrm{Ca}^{2+}$ similares a los observados en fibras neonatales, independientemente de la edad del músculo de origen del cultivo (Figueroa LC, Bolaños P, Caputo C. $\mathrm{Ca}^{2+}$ signaling during development of muscle fibers and primary culture myotubes. Biophy J. 2007; 311a).

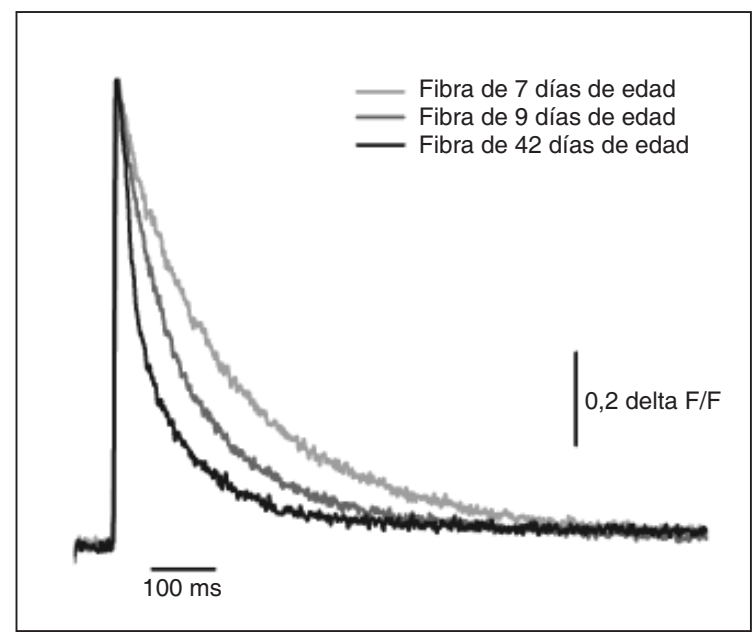

Figura 3. Transitorios de calcio representativos normalizados de fibras de FDB de ratones a distintas edades postnatales y adultos; obtenidos con el indicador Fluo4-AM. Obsérvese cómo a medida que aumenta la edad del ratón ocurre una disminución en el ancho medio y en la constante de tiempo de caída, así como un aumento en la relación delta F/F y una disminución en el tiempo de subida (no se presentan los datos).
Actualmente se investigan los posibles mecanismos de regulación y la importancia fisiológica que pudiese tener el $\mathrm{Ca}^{2+}$ extracelular en el acoplamiento excitación-contracción en fibras esqueléticas, que buscan relacionar la distribución de los túbulos $\mathrm{T}$ y de los receptores de dihidropiridinas y los de rianodina con los mecanismos de liberación y remoción de $\mathrm{Ca}^{2+}$ intracelular observados en distintas etapas del desarrollo neonatal.

\section{Modulación farmacológica}

Iones como el cinc y el nitrato aumentan la salida de $\mathrm{Ca}^{2+}$ del retículo sarcoplásmico al aumentar el tiempo que la fibra permanece activada durante el potencial de acción, lo cual potencia la respuesta durante una sacudida simple (154, Calderón \& Caputo, 2007, resultados sin publicarse; figura 4); dichos compuestos pueden modular las propiedades de inactivación de los canales de $\mathrm{Ca}^{2+}$ (Caputo \& Bolaños, 2007, resultados sin publicarse). A pesar de esto, no parecen cambiar las propiedades de capacidad de fatiga de las fibras musculares de ratón (Calderón \& Caputo, 2007, resultados sin publicarse).

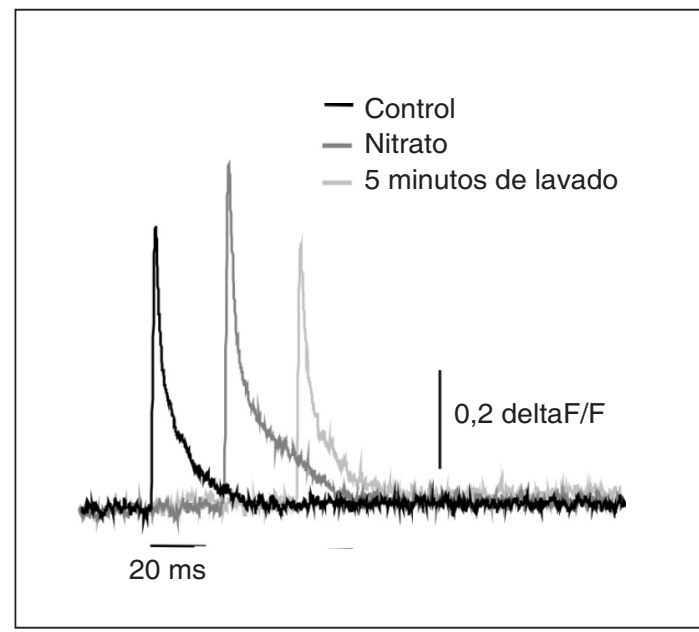

Figura 4. Cinética del transitorio de calcio de una fibra de flexor digitorum brevis disociada enzimáticamente, bajo condiciones control (solución de Ringer) y expuesta a nitrato, obtenido con MagFluo4-AM. Obsérvese la potenciación del transitorio (aumento de la amplitud), el cambio de la Tau 2 y la reversibilidad del efecto al lavar con solución de Ringer. 
Otros iones, como bromuro, yoduro y algunos cationes divalentes, también son potenciadores de la tensión producida durante una sacudida simple (3). No se conoce el efecto de estos moduladores del acoplamiento excitacióncontracción sobre la inactivación de los canales de $\mathrm{Ca}^{2+}$ ni sobre la resistencia a la fatiga de las fibras musculares.

\section{Otras preguntas}

Se sabe que la hipertermia maligna es causada por alteraciones del receptor de rianodina 1; sin embargo, hay un porcentaje de casos que no son explicados por las mutaciones conocidas (47). Podría haber mutaciones en otras proteínas de la unidad liberadora de $\mathrm{Ca}^{2+}$ que se asocien a enfermedad. Recientemente se ha sugerido que alteraciones en la regulación del receptor de rianodina 2 pueden ser un factor importante en la fisiopatología de la falla cardíaca (155), una hipótesis que no ha sido confirmada por otros grupos (156). Las investigaciones en esta área, además, deben explorar el potencial de las diferentes proteínas del acoplamiento excitacióncontracción como blanco terapéutico.

La calsecuestrina es la proteína con capacidad de unir $\mathrm{Ca}^{2+}$ más abundante en el retículo sarcoplásmico. Se ha reconocido como una proteína reguladora del receptor de rianodina al prevenir el vaciamiento del retículo sarcoplásmico, mediante un mecanismo que depende de cambios en la conformación de la proteína y de interacciones con el complejo receptor de rianodina-triadina-junctina $(11,27)$. Esto, sin embargo, ha sido recientemente cuestionado por trabajos en los que tanto la expresión exagerada como el silenciamiento de la calsecuestrina 1 en músculo esquelético tienen efectos funcionales mínimos (Royer L, Pouvreau S, Wang Y, Meissner G, Zhou J, Volpe P, et al. Functional and structural consequences of transiently increasing calsequestrin concentration by $\sim 700 \%$ in mouse skeletal muscle. Biophys J. 2008;94:99-100a; Royer L, Pouvreau S, Wang Y, Meissner G, Zhou J, Nori A, et al. The effect of severe knockdown of calsequestrin 1 in adult mammalian muscle. Biophys J. 2008;94:538a). Esta aparente contradicción, así como la compleja regulación del receptor de rianodina por el complejo receptor de rianodina-triadina-junctina-calsecuestrina y otras proteínas como la recién caracterizada SRP-27 (28), merece más estudios.

Entre las preguntas que aún permanecen sin responder, varias están relacionadas con los mecanismos de remoción del $\mathrm{Ca}^{2+}$ citoplásmico una vez que ocurre la activación contráctil. Se ha aceptado que la relajación de la fibra muscular esquelética es consecuencia de la activación de la SERCA del retículo sarcoplásmico y de la unión del $\mathrm{Ca}^{2+}$ a la parvalbúmina. Sin embargo, en los últimos años se ha propuesto la participación de las mitocondrias y del intercambiador $\mathrm{Na}^{+}-\mathrm{Ca}^{2+}$ en este proceso, ya que ambos se encuentran involucrados en la regulación de la homeostasis de $\mathrm{Ca}^{2+}$ en otros tipos celulares, excitables y no excitables (157).

En el caso de las mitocondrias, existen diversas evidencias que señalan su contribución a largo plazo en la homeostasis de $\mathrm{Ca}^{2+}$ de fibras musculares esqueléticas $(63,158,159)$; no obstante, esto no se acepta universalmente. Por su parte, aunque existen pruebas del funcionamiento del intercambiador $\mathrm{Na}^{+}-\mathrm{Ca}^{2+}$ en el músculo esquelético, su papel en el acoplamiento excitación-contracción ha sido poco estudiado (160-162). Resultados recientes del Laboratorio de Fisiología Celular del Instituto Venezolano de Investigaciones Científicas le adjudican un papel importante al intercambiador $\mathrm{Na}^{+}-\mathrm{Ca}^{2+}$ cuando la SERCA se encuentra saturada, como sucede cuando se estimula continuamente con tétanos una fibra muscular (Manno $\mathrm{C}$, Bolanos $\mathrm{P}$, Caputo C. Importance of NCX in the regulation of $\mathrm{Ca}^{2+}$ homeostasis in skeletal muscle. Biophys J. 2008:305a). La ausencia de resultados o la discrepancia entre algunos de ellos claramente indican la necesidad de obtener mayor información al respecto.

\section{Agradecimientos}

A Carlo Caputo, Ph.D. y a la licenciada Pura Bolaños, del Laboratorio de Fisiología Celular del Instituto Venezolano de Investigaciones Científicas, por la revisión del texto y la facilitación de resultados y figuras. 


\section{Conflicto de intereses}

No hay conflictos de intereses.

\section{Financiamiento}

El financiamiento proviene de la Universidad de Antioquia, Medellín, Colombia, (JCCV) y del Instituto Venezolano de Investigaciones Científicas, Venezuela, (LCFG).

\section{Referencias}

1. Kahn A, Sandow A. The potentiation of muscular contraction by the nitrate-ion. Science. 1950;112:647-9.

2. Sandow A. Excitation-contraction coupling in muscular response. Yale J Biol Med. 1952;XXV:176-201.

3. Caputo C. Pharmacological investigations of excitationcontraction coupling. Chapter 14. En: Peachey L, Adrian R, editors. Handbook of physiology. Bethesda: American Physiological Society; 1983.

4. Berridge $\mathbf{M}$, Lipp $\mathbf{P}$, Bootman $\mathbf{M}$. The versatility and universality of calcium signaling. Nature Rev Mol Cell Biol. 2000;1:11-21.

5. Weber A. On the role of calcium in the activity of adenosine $5^{\prime}$-triphosphate hydrolysis by actomyosin. J Biol Chem. 1959;234:2764-9.

6. Niedergerke R. Local muscular shortening by intracellularly applied calcium. J Physiol. 1955;128:12P3P.

7. Hasselbach W. Relaxing factor and the relaxation of muscle. Prog Biophys Mol Biol. 1964;14:167-222.

8. Endo M, Tanaka M, Ogawa Y. Calcium induced release of calcium from the sarcoplasmic reticulum of skinned skeletal muscle fibres. Nature. 1970;228:34-6.

9. Ebashi S. Calcium ion and contractile proteins. Ann NY Acad Sci USA. 1988;522:51-9.

10. Stephenson D, Lamb G, Stephenson G. Events of the excitation-contraction-relaxation (E-C-R) cycle in fastand slow-twitch mammalian muscle fibres relevant to muscle fatigue. Acta Physiol Scand. 1998;162:229-45.

11. Fill M, Copello J. Ryanodine receptor calcium release channels. Physiol Rev. 2002;82:893-922.

12. Horowicz P. Influence of ions on the membrane potential of muscle fibres. En: Shanes A, editor. Biophysics of physiological and pharmacological actions. Washington: American Association for the Advancement of Science; 1961. p. 217-34.

13. Hodgkin A, Huxley A. A quantitative description of membrane current and its application to conduction and excitation in nerve. J Physiol. 1952;117:500-44.

14. González-Serratos H. Inward spread of activation in vertebrate muscle fibres. J Physiol. 1971;212:777-99.
15. Bezanilla F, Caputo C, González-Serratos H, Venosa R. Sodium dependence of the inward spread of activation in isolated twitch muscle fibres of the frog. J Physiol. 1972;223:507-23.

16. Franzini-Armstrong C, Porter K. Sarcolemmal invaginations constituting the $\mathrm{T}$ system in fish muscle fibres. J Cell Biol. 1964;22:675-96.

17. Schneider M, Chandler W. Voltage dependent charge movement in skeletal muscle: a possible step in excitationcontraction coupling. Nature. 1973;242:244-6.

18. Ríos E, Brum G. Involvement of dihydropyridine receptors in excitation-contraction coupling in skeletal muscle. Nature. 1987;325:717-20.

19. Ríos E, Pizarro G. Voltage sensor of excitationcontraction coupling in skeletal muscle. Physiol Rev. 1991;71:849-908.

20. Bezanilla $\mathbf{F}$. The voltage sensor in voltage-dependent ion channels. Physiol Rev. 2000;80:555-92.

21. Lai F, Erickson H, Rousseau E, Liu Q, Meissner G. Purification and reconstitution of the calcium release channel from skeletal muscle. Nature. 1988; 331:315-9.

22. Takeshima $\mathbf{H}$, Nishimura $\mathbf{S}$, Matsumoto $\mathbf{T}$, Ishida $\mathbf{H}$, Kangawa K, Minamino N, et al. Primary structure and expression from complementary DNA of skeletal muscle ryanodine receptor. Nature. 1989;339:439-45.

23. Franzini-Armstrong C, Jorgensen A. Structure and development of e-c coupling units in skeletal muscle. Annu Rev Physiol. 1994;56:509-34.

24. Franzini-Armstrong $\mathbf{C}$. The sarcoplasmic reticulum and the control of muscle contraction. FASEB J. 1999;13(Suppl):S266-S70.

25. Meissner G. Adenine nucleotide stimulation of $\mathrm{Ca}^{2+}$ induced $\mathrm{Ca}^{2+}$ release in sarcoplasmic reticulum. $\mathrm{J}$ Biol Chem. 1984;259:2365-74.

26. Coronado R, Morrissette J, Sukhareva, Vaughan D. Structure and function of ryanodine receptors. Am J Physiol. 1994;266:C1485-504.

27. Wei L, Varsányi M, Dulhunty A, Beard N. The conformation of calsequestrin determines its ability to regulate skeletal ryanodine receptors. Biophys $\mathrm{J}$. 2006;91:1288-301.

28. Bleunven C, Treves S, Jinyu X, Leo E, Ronjat M, De Waard M, et al. SRP-27 is a novel component of the supramolecular signaling complex involved in skeletal muscle excitation-contraction coupling. Biochem J. 2008;411:343-49.

29. Prosser B, Wright N, Hernández-Ochoa E, Varney K, Liu Y, Olojo R, et al. S100A1 binds to the calmodulin binding site of ryanodine receptor and modulates skeletal muscle coupling. J Biol Chem. 2008;283:5046-57.

30. Fabiato A. Dependence of the $\mathrm{Ca}^{2+}$-induced release from the sarcoplasmic reticulum of skinned skeletal muscle 
fibres from the frog semitendinosus on the rate of change of free $\mathrm{Ca}^{2+}$ concentration at the outer surface of the sarcoplasmic reticulum. J Physiol. 1984;353-6P.

31. Baylor S, Hollingwoth S. Sarcoplasmic reticulum calcium release compared in slow-twitch and fast-twitch fibres of mouse muscle. J Physiol. 2003;551:125-38.

32. Caputo C, Bolaños $\mathbf{P}$, González A. Inactivation of Ca2+ transients in amphibian and mammalian muscle fibres. $\mathrm{J}$ Muscle Res Cell Motil. 2004;25:315-28.

33. Miledi R, Parker I, Schalow G. Calcium transients in frog slow muscle fibres. Nature. 1977;268:750-2.

34. Klein M, Simon B, Szucs G, Schneider M. Simultaneous recording of calcium transients in skeletal muscle using high and low-affinity calcium indicators. Biophys $\mathrm{J}$. 1988;53:971-88.

35. Delbono O, Stefani E. Calcium transients in single mammalian skeletal muscle fibres. J Physiol. 1993; 463: 689-707.

36. Shirokova N, García J, Pizarro G, Rios E. $\mathrm{Ca}^{2+}$ release from the sarcoplasmic reticulum compared in amphibian and mammalian skeletal muscle. J Gen Physiol. 1996;107:1-18.

37. Ebashi S. Regulatory mechanism of muscle contraction with special reference to the Ca-troponin-tropomyosin system. Essays Biochem. 1974;10:1-36.

38. Berchtold $\mathbf{M}$, Brinkmeier $\mathbf{H}$, Müntener $\mathbf{M}$. Calcium ion in skeletal muscle: its crucial role for muscle function, plasticity, and disease. Physiol Rev. 2000;80:1215-65.

39. Hasselbach W, Suko J, Stromer M, The R. Mechanism of calcium transport in sarcoplasmic reticulum. Ann NY Acad Sci. 1975;264:335-49.

40. Jorgensen A, Jones L. Localization of phospholamban in slow but not fast canine skeletal muscle fibers. J Biol Chem. 1986;261:3775-81.

41. Hasselbach W. The $\mathrm{Ca}^{2+}-\mathrm{ATP}$ ase of the sarcoplasmic reticulum in skeletal and cardiac muscle. Ann NY Acad Sci. 1998;853:1-8.

42. Odermatt A, Becker S, Khanna V, Kurzydlowski K, Leisner E, Pette D, et al. Sarcolipin regulates the activity of SERCA1, the fast-twitch skeletal muscle sarcplasmic reticulum $\mathrm{Ca}^{2+}$-ATPase. J Biol Chem. 1998;273:12360-9.

43. Martonosi A, Pikula S. The structure of the $\mathrm{Ca}^{2+}$ ATPase of sarcoplasmic reticulum. Acta Biochim Pol. 2003;50:337-65

44. Periasamy M, Kalyanasundaram A. Serca pump isoforms: their role in calcium transport and disease. Muscle Nerve. 2007;35:430-42.

45. Toyoshima H, Mizutani T. Crystal structure of the calcium pump with a bound ATP analogue. Nature. 2004;430:529-35.

46. MacLennan D, Brandl C, Korczak B, Green N. Aminoacid sequence of a $\mathrm{Ca}^{2+}+\mathrm{Mg}^{2+}$-dependent ATPase from rabbit muscle sarcoplasmic reticulum, deduced from its complementary DNA sequence. Nature. 1985;316:696700.

47. Dulhunty A. Excitation-contraction coupling from the 1950s into the new millennium. Clin Exp Pharmacol Physiol. 2006;33:763-72.

48. Bekoff A, Betz W. Physiological properties of dissociated muscle fibres obtained from innervated and denervated adult rat muscle. J Physiol. 1977;271:25-40.

49. Lännergren J, Westerblad $\mathbf{H}$. The temperature dependence of isometric contractions of single, intact fibres dissected from a mouse foot muscle. J Physiol. 1987;390:285-93.

50. Wood DS, Zollman J, Reuben JP. Human skeletal muscle properties of the "chemically skinned" fiber. Science. 1975;187:1075-6.

51. Lamb G, Junankar $\mathbf{P}$, Stephenson D. Raised intracellular $\mathrm{Ca}^{2+}$ abolishes excitation-contraction coupling in skeletal muscle fibres of rat and toad. J Physiol. 1995;489:34962.

52. Lamb G. Excitation-contraction coupling and fatigue mechanisms in skeletal muscle: studies with mecanically skinned fibres. J Muscle Res Cell Motil. 2002;23:81-91.

53. Yaffe D, Saxel O. Serial passaging and differentiation of myogenic cells isolated from dystrophic mouse muscle. Nature. 1977;270:725-7.

54. Rando TA, Blau HM. Primary mouse myoblast purification, characterization and transplantation for cell-mediated gene therapy. J Cell Biol. 1994;125:1275-87.

55. Ridgway E, Ashley C. Calcium transients in single muscle fibres. Biochem Biophys Res Commun. 1967;29:229-34.

56. Grynkiewicz G, Poenie M, Tsien R. A new generation of $\mathrm{Ca}^{2+}$ indicators with greatly improved fluorescence properties. J Biol Chem. 1985;260:3440-50.

57. Minta A, Kao J, Tsien R. Fluorescent indicators for cytosolic calcium based on rhodamine and fluorescein chromophores. J Biol Chem. 1989;264:8171-8.

58. Takahashi A, Camacho P, Lechleiter J, Herman B. Measurement of intracellular calcium. Physiol Rev. 1999;79:1089-125.

59. Katerinopoulos H, Foukaraki E. Polycarboxylate fluorescent indicators as ion concentration probes in biological systems. Current Med Chem. 2002;9:275-306.

60. Tsien R. A non-disruptive technique for loading calcium buffers and indicators into cells. Nature. 1981;290:527-8.

61. Pouvreau S, Collet C, Allard B, Jacquemond V. Wholecell voltage clamp on skeletal muscle fibers with siliconeclamp technique. Meth Mol Biol. 2007;403:185-94.

62. Beam K, Franzini-Armstong C. Functional and structural approaches to the study of excitation-contraction coupling. Methods Cell Biol. 1997;52:283-306. 
63. Bolaños $\mathbf{P}$, Guillén $\mathbf{A}$, Rojas $\mathbf{H}$, Boncompagni $\mathbf{S}$, Caputo $\mathbf{C}$. The use of CalciumOrange-5N as a specific marker of mitochondrial $\mathrm{Ca}^{2+}$ in mouse skeletal muscle fibers. Pflugers Arch-Eur J Physiol. 2008;455:721-31.

64. Cheng H, Lederer W, Cannell M. Calcium sparks: elementary events underlying excitation-contraction coupling in heart muscle. Science. 1993;262:740-4.

65. Klein M, Schneider M. $\mathrm{Ca}^{2+}$ sparks in skeletal muscle. Prog Biophys Mol Biol. 2006;92:308-32.

66. Papadopoulus S, Leuranguer V, Bannister R, Beam K. Mapping sites of potential proximity between the DHPR and RyR1 in muscle using a cyan fluorescent proteinyellow fluorescent protein tandem as a fluorescent resonance energy transfer probe. $\mathrm{J}$ Biol Chem. 2004;279:44046-56.

67. Launikonis BS, Zhou J, Royer L, Shannon T, Brum G, Rios E. Confocal imaging of $\left[\mathrm{Ca}^{2+}\right]$ in cellular organelles by SEER, shifted excitation and emission ratioing of fluorescence. J Physiol. 2005;567:523-43.

68. Serysheva I, Chiu W, Ludtke S. Single-particle electron cryomicroscopy of the ion channels in the excitationcontraction coupling junction. Methods Cell Biol. 2007;79:407-35

69. Anderson A, Altafaj X, Zheng Z, Wang Z, Delbono O, Ronjat M, et al. The junctional SR protein JP-45 affects the functional expression of the voltage-dependent $\mathrm{Ca}^{2+}$ channel Cav1.1. J Cell Sci. 2006;119:2145-55.

70. DiFranco M, Neco P, Capote J, Meera P, Vergara J. Quantitative evaluation of mammalian skeletal muscle as a heterologous protein expression system. Protein Expr Purif. 2006;47:281-8.

71. Flucher B, Franzini-Armstrong C. Formation of junctions involved in excitation-contraction coupling in skeletal and cardiac muscle. Proc Natl Acad Sci USA. 1996;93:8101-6.

72. Ríos E, Karhanek M, Ma J, González A. An Allosteric model of the molecular interactions of excitationcontraction coupling in skeletal muscle. J Gen Physiol. 1993;102:449-81.

73. Wagenknecht T, Grassucci R, Frank J, Saito A, Inui $\mathbf{M}$, Fleischer $\mathbf{S}$. Three-dimensional architecture of the calcium channel/foot structure of sarcoplasmic reticulum. Nature. 1989;338:167-70.

74. Ávila G, Dirksen R. Functional impact of the ryanodine receptor on the skeletal muscle L-type $\mathrm{Ca}^{2+}$ channel. J Gen Physiol. 2000;114: 467-80.

75. Wagenknecht T, Hsieh C-E, Rath B, Fleischer S, Marko M. Electron tomography of frozen-hydrated isolated triad junctions. Biophys J. 2002;83:2491-501.

76. Paolini C, Fessenden J, Pessah I, FranziniArmstrong C. Evidence for conformational coupling between two calcium channels. Proc Natl Acad Sci USA. 2004;101:12748-52.
77. Tanabe T, Beam K, Adams B, Niidome T, Numa S. Regions of the skeletal dihydropyridine receptor critical for excitation-contraction coupling. Nature. 1990;346:567-9.

78. Leong P, MacLennan D. A 37-amino acid sequence in the skeletal muscle ryanodine receptor interacts with the cytoplasmic loop between domains II and III in the skeletal muscle dihydropyridine receptor. J Biol Chem. 1998;273:7791-4.

79. Casarotto M, Cui Y, Karunasekara Y, Harvey P, Norris N, Borrad P, et al. Structural and functional characterization of interactions between the dihydropyridine receptor IIIII loop and the ryanodine receptor. Clin Exp Pharmacol Physiol. 2006;33:1114-7.

80. Protasi F, Paolini C, Nakai J, Beam K, FranziniArmstrong C, Allen P. Multiple regions of RyR1 mediate functional and structural interactions with $01 \mathrm{~s}$ dihidropyridine receptors in skeletal muscle. Biophy J. 2002;83:3220-44.

81. Ludtke S, Serysheva I, Hamilton S, Chiu W. The pore structure of the closed RyR1 channel. Structure. 2005;13:1203-11.

82. Samsó M, Wagenknecht T, Allen D. Internal structure and visualization of transmembrane domains of the RyR1 calcium release channel by cryo-EM. Nat Struct Mol Biol. 2005;12:539-44.

83. Doyle D, Morais Cabral J, Pfuetzner R, Kuo A, Gulbis J, Cohen S, et al. The structure of potassium channel: molecular basis of $\mathrm{K}^{+}$conduction and selectivity. Science. 1998;280:69-77.

84. Jiang Y, Lee A, Chen J, Cadene M, Chalt B, MacKinnon R. The open pore conformation of potassium channels. Nature. 2002;417:523-6.

85. Zorzato F, Fujii J, Otsu M, Phillips M, Green N, Lai F, et al. Molecular cloning of CDNA encoding human and rabbit forms of the $\mathrm{Ca}^{2+}$ release channel (ryanodine receptor) of skeletal muscle sarcoplasmic reticulum. J Biol Chem. 1990;265: 2244-56.

86. Fitts R. Cellular mechanisms of muscle fatigue. Physiol Rev. 1994;74:49-94.

87. Enoka R, Duchateau J. Muscle fatigue: what, why and how it influences muscle function. J Physiol. 2008;586:1123.

88. Allen D, Lamb G, Westerblad. Skeletal muscle fatigue: cellular mechanisms. Physiol Rev. 2008;88:287-332.

89. Bigland-Ritchie B, Woods J. Changes in muscle contractile properties and neural control during human muscular fatigue. Muscle Nerve. 1984;7:691-9.

90. Abbiss C, Laursen P. Models to explain fatigue during prolonged endurance cycling. Sports Med. 2005;35:86598.

91. Kent-Braun J. Central and peripheral contributions to muscle fatigue in humans during sustained maximal effort. Eur J Appl Physiol. 1999;80:57-63. 
92. Luttgau $\mathbf{H}$. The effect of metabolic inhibitors on the fatigue of the action potential in single muscle fibres. J Physiol. 1965;178:45-67.

93. Grabowski W, Lobsiger E, Luttgau H. The effect of repetitive stimulation at low frequencies upon the electrical and mechanical activity of single muscle fibres. Pflugers Arch. 1972;334:222-39.

94. Moussavi R, Carson P, Boska M, Weiner M, Miller R. Nonmetabolic fatigue in exercising human muscle. Neurology. 1989;39:1222-26.

95. Nassar-Gentina V, Passonneau J, Vergara J, Rapoport S. Metabolic correlates of fatigue and recovery from fatigue in single frog muscle fibers. J Gen Physiol. 1978;72:593-606.

96. Westerblad H, Allen D. Changes of myoplasmic calcium concentration during fatigue in single mouse muscle fibers. J Gen Physiol. 1991;98:615-35.

97. Green H. Cation pumps in skeletal muscle: potential role in muscle fatigue. Acta Physiol Scand. 1998;162:201-13.

98. Hill A, Kupalov P. Anaerobic and aerobic activity in isolated muscle. Proc R Soc London B. 1929;105:313-22.

99. Westerblad $\mathbf{H}$. The role of $\mathrm{pH}$ and inorganic phosphate ions in skeletal muscle fatigue. Chapter 12. En: Hargreaves $M$, Thompson $M$, editors. Biochemistry of exercise $X$. Champaign: Human Kinetics; 1999. p. 147-54.

100. Westerblad H, Allen D, Lännergren J. Muscle fatigue: lactic acid or inorganic phosphate the major cause? News Physiol Sci. 2002;17:17-21.

101. Lamb G, Stephenson D. Lactic acid accumulation is an advantage during muscle activity. J Appl Physiol. 2006;100:1410-2.

102. Bangsbo J, Juel C. Lactic acid accumulation is a disadvantage during muscle activity. J Appl Physiol. 2006;100:1412-3.

103. McCully K, Clark B, Kent J, Wilson J, Chance B. Biochemical adaptations to training: implications for resisting muscle fatigue. Can J Physiol Pharmacol. 1991;69:274-8

104. Lindinger M, Heigenhauser G. The roles of ion fluxes in skeletal muscle fatigue. Can J Physiol Pharmacol. 1991;69:246-53.

105. Kent-Braun J, Miller R, Weiner M. Phases of metabolism during progressive exercise to fatigue in human skeletal muscle. J Appl Physiol. 1993;75:573-80.

106. Knuth S, Dave H, Peters J, Fitts R. Low cell pH depresses peak power in rat skeletal muscle fibres at both $30^{\circ} \mathrm{C}$ and $15^{\circ} \mathrm{C}$ : implications for muscle fatigue. $\mathrm{J}$ Physiol. 2006;575:887-99.

107. Rousseau E, Pinkos J. pH modulates conducting and gating behaviour of single calcium release channels. Pflugers Arch-Eur J Physiol. 1990;415:645-7.
108. Caputo C, Edman K, Lou F, Sun Y. Variation in myoplasmic $\mathrm{Ca}$ concentration during contraction and relaxation studied by the indicator fluo-3 in frog muscle fibres. J Physiol. 1994;478:137-48.

109. Verburg E, Murphy R, Stephenson G, Lamb G. Disruption of excitation-contraction coupling and titin by endogenous $\mathrm{Ca} 2+-$ activated proteases in toad muscle fibres. J Physiol. 2005;564:775-89.

110. Gollnick P, Korge P, Karpakka J, Saltin B. Elongation of skeletal muscle relaxation during exercise is linked to reduced calcium uptake by the sarcoplasmic reticulum in man. Acta Physiol Scand. 1991;142:135-6.

111. Leppik J, Aughey R, Medved I, Fairweather I, Carey M, McKenna M. Prolongued exercise to fatigue in humans impairs skeletal muscle Na-K ATPase activity, sarcoplasmic reticulum $\mathrm{Ca}$ release and $\mathrm{Ca}$ uptake. J Appl Physiol. 2004;97:1414-23.

112. Verburg E, Dutka T, Lamb G. Long-lasting muscle fatigue: partial disruption of excitation-contraction coupling by elevated cytosolic $\mathrm{Ca}^{2+}$ concentration during contractions. Am J Physiol. 2006;290:C1199-C208.

113. Westerblad H, Allen D. Myoplasmic free $\mathrm{Mg}^{2+}$ concentration during repetitive stimulation of single fibres from mouse skeletal muscle. J Physiol. 1992;453:41334.

114. Lamb G, Stephenson D. Effects of intracellular $\mathrm{pH}$ and $\left[\mathrm{Mg}^{2+}\right]$ on excitation-contraction coupling in skeletal muscle fibres of the rat. J Physiol. 1994; 478:331-9.

115. Fryer M, Owen V, Lamb G, Stephenson G. Effects of creatine phosphate and $\mathrm{Pi}$ on $\mathrm{Ca}$ movements and tension development in rat skinned skeletal muscle fibres. J Physiol. 1995;482:123-40.

116. Dutka T, Cole L, Lamb G. Calcium phosphate precipitation in the sarcoplasmic reticulum reduces action potential-mediated $\mathrm{Ca}^{2+}$ release in mammalian skeletal muscle. Am J Physiol. 2005;289:C1502-C12.

117. Barclay J, Hansel M. Free radicals may contribute to oxidative skeletal muscle fatigue. Can J Physiol Pharmacol. 1991;69:279-84.

118. Sen C. Oxidants and antioxidants in exercise. J Appl Physiol. 1995;79:675-86.

119. Reid M. Plasticity in skeletal, cardiac, and smooth muscle. Invited review: Redox modulation of skeletal muscle contraction: what we know and what we don't. J Appl Physiol. 2001;90:724-31.

120. Darnley G, Duke A, Steele D, MacFarlane N. Effects of reactive oxygen species on aspects of excitationcontraction coupling in chemically skinned rabbit diaphragm muscle fibres. Exp Physiol. 2001;86:161-8.

121. Davies K, Quintanilha A, Brooks G, Packer L. Free radicals and tissue damage produced by exercise. Biochem Biophys Res Commun. 1982;107:1198-205. 
122. M, Haack K, Kathleen F, Valberg P, Kobzik L, West S. Reactive oxygen in skeletal muscle. I. Intracellular oxidant kinetics and fatigue in vitro. J Appl Physiol. 1992;73:1797-804

123. Kanter M, Nolte L, Holloszy J. Effects of an antioxidant vitamin mixture on lipid peroxidation at rest and postexercise. J Appl Physiol. 1993;74:965-9.

124. Jackson M, Pye D, Palomero J. The production of reactive oxygen species by skeletal muscle. J Appl Physiol. 2007;102:1664-70.

125. Brotto M, Nosek T. Hydrogen peroxide disrupts $\mathrm{Ca}^{2+}$ release from the sarcoplasmic reticulum of rat skeletal muscle fibers. J Appl Physiol. 1996;81:731-7.

126. Oba T, Kurono C, Nakajima R, Takaishi T, Ishida $\mathbf{K}$, Fuller G, et al. $\mathrm{H}_{2} \mathrm{O}_{2}$ activates ryanodine receptor but has little effect on recovery of release $\mathrm{Ca}^{2+}$ content after fatigue. J Appl Physiol. 2002;93:1999-2008.

127. Hidalgo C. Cross talk between $\mathrm{Ca}^{2+}$ and redox signaling cascades in muscle and neurons through the combined activation of ryanodine receptors $/ \mathrm{Ca}^{2+}$ release channels. Phil Trans R Soc B. 2005;360:2237-46.

128. Moopanar T, Allen D. Reactive oxygen species reduce myofibrillar $\mathrm{Ca}^{2+}$ sensitivity in fatiguing mouse skeletal muscle at $37^{\circ} \mathrm{C}$. J Physiol. 2005;564:189-99.

129. Moopanar T, Allen D. The activity-induced reduction of myofibrillar $\mathrm{Ca}^{2+}$ sensitivity in Mouse skeletal muscle is reversed by dithiothreitol. J Physiol. 2006;571:191-200.

130. Posterino G, Lamb G. Effects of reducing agents and oxidants on excitation-contraction coupling in skeletal muscle fibres of rat and toad. J Physiol. 1996;496:80925

131. Andrade F, Reid M, Allen D, Westerblad H. Effects of hydrogen peroxide and dithiotreitol on contractile function of single skeletal muscle fibres from the mouse. J Physiol. 1998;509:565-75

132. Andrade F, Reid M, Allen D, Westerblad H. Effect of nitric oxide on single skeletal muscle fibres from the mouse. J Physiol. 1998;509:577-86.

133. Andrade F, Reid M, Westerblad H. Contractile response of skeletal muscle to low peroxide concentrations: myofibrillar calcium sensitivity as a likely target for redoxmodulation. FASEB J. 2001;15:309-11.

134. Ward K, Wareham A. Changes in membrane potential and potassium and sodium activities during postnatal development of mouse skeletal muscle. Exp Neurol. 1985;89:554-8.

135. Brown M, Jansen J, Van Essen D. Polyneural innervation of skeletal muscle in newborn rats and its elimination during maturation. J Physiol. 1976;261:387422.

136. Kjeldsen K, Norgaard A, Clausen T. Age dependent changes in the number of $[\mathrm{H}]$ ouabain binding sites in rat soleus muscle. Biochem Biophys Acta. 1982;686:253356.

137. Harris J, Marshall M. Tetrodotoxin-resistant action potentials in newborn rat muscle. Nature New Biol. 1973;243:191-2.

138. Capote J, Bolanos P, Schuhmeier R, Melzer W, Caputo C. Calcium transients in developing mouse skeletal muscle fibres. J Physiol. 2005;564:451-64.

139. Kano M, Yamamoto M. Development of spike potentials in skeletal muscle cells differentiated in vitro from chick embryo. J Cell Physiol. 1977;90:439-44.

140. Franzini-Armstrong C. Simultaneous maturation of transverse tubules and sarcoplasmic reticulum during muscle differentiation in the mouse. Dev Biol. 1991;146:353-63.

141. Bertocchini F, Ovitt C, Conti A, Barone V, Schöler $\mathbf{H}$, Bottinelli $\mathbf{R}$, et al. Requirement for the ryanodine receptor type 3 for efficient contraction in neonatal skeletal muscles. EMBO J. 1997;16:6956-63.

142. Chaudhari N, Beam K. mRNA for cardiac calcium channels is expressed during development of skeletal muscle. Dev Biol. 1993;155:507-15.

143. Cognard C, Lazdunski M, Romey G. Different types of $\mathrm{Ca}^{2+}$ channels in mammalian skeletal muscle cells in culture. Proc Natl Acad Sci USA. 1986;83:517-21.

144. Beam K, Knudson C. Calcium currents in embryonic and neonatal mammalian skeletal muscle. J Gen Physiol. 1988;91:781-98.

145. Beam K, Knudson C. Effect of postnatal development on calcium currents and slow charge movement in mammalian skeletal muscle. J Gen Physiol. 1988;91:799815.

146. Romey G, Garcia L, Dimitriadou V, Pincon-Raymond M, Rieger F, Lazdunski M. Ontogenesis and localization of $\mathrm{Ca}$ channels in mammalian skeletal muscle in culture and role in excitation-contraction coupling. Proc Natl Acad Sci USA. 1989;86:2933-7.

147. Dangain J, Neering I. Effect of caffeine and high potassium on normal and dystrophic mouse EDL muscles at various developmental stages. Muscle Nerve. 1992;16:33-42.

148. Ma J, Pan Z. Retrograde activation of store-operated calcium channel. Cell Calcium. 2003;33:375-84.

149. Whalen R, Sell S, Butler-Browne G, Schwartz K, Bouveret P, Pinset-Harstom I. Three myosin heavychain isozymes appear sequentially in rat muscle development. Nature. 1981;292:805-9.

150. Dhoot G, Perry S. The components of the troponin complex and development in skeletal muscle. Exp Cell Res. 1980;127:75-87.

151. Roy R, Sreter F, Sarkar S. Changes in tropomyosin subunits and myosin light chains during development 
of chicken and rabbit striated muscles. Dev Biol. 1979;69:15-30.

152. Berchtold M, Means A. The $\mathrm{Ca}^{2+}$-binding protein parvalbumin: molecular cloning and developmental regulation of mRNA abundance. Proc Natl Acad Sci USA. 1985;82:1414-8.

153. Figueroa LC, Bolaños P, Guillen A, Caputo C. Efecto del calcio extracelular sobre transitorios de $\mathrm{Ca}^{2+}$ de fibras musculares esqueléticas y miotubos durante el desarrollo. Acta Científica Venezolana. 2006;57:19.

154. Sandow A, Taylor S, Preiser H. Role of the action potential in excitation-contraction coupling. Fed Proc. 1965;24:1116-23.

155. Marx S, Reiken S, Hisamatsu Y, Jayaraman T, Burkhoff D, Rosemblit N, et al. PKA phosphorylation dissociates FKBP12.6 from the calcium release channel (ryanodine receptor): defective regulation in failing hearts. Cell. 2000;101:365-76.

156. Stange M, Xu L, Balshaw D, Yamaguchi N, Meissner G. Characterization of recombinant skeletal muscle (Ser2843) and cardiac muscle (Ser-2809) ryanodine receptor phosphorylation mutants. J Biol Chem. 2003;278:51693702.
157. Dipolo R, Beaugé L. Sodium/calcium exchanger: influence of metabolic regulation on ion carrier interaction. Physiol Rev. 2006;86:155-203.

158. Bruton J, Tavi P, Aydin J, Wasterblad H, Lanergren J. Mitochondrial and myoplasmic $\left[\mathrm{Ca}^{2+}\right]$ in single fibers from Mouse limb muscles during repeated tetanic contraction. J Physiol. 2003;551:179-90.

159. Caputo C, Bolaños P. Effect of mitochondria poisoning by FCCP on $\mathrm{Ca}^{2+}$ signaling in muse skeletal muscle fibers. Pflugers Arch-Eur J Physiol. 2008;455:733-43.

160. Caputo C, Bolaños P. Effect of external sodium and calcium on calcium efflux in frog striated muscle. $\mathrm{J}$ Membr Biol. 1978;41:1-14.

161. Balnave Ch, Allen D. Evidence for $\mathrm{Na}+/ \mathrm{Ca} 2+$ Exchange in intact single skeletal muscle fibers from the mouse. Am J Physiol Cell Physiol. 1998;274:940-6.

162. Cifuentes F, Vergara J, Hidalgo C. Sodium/calcium Exchange in amphibian skeletal muscle fibers and isolated transverse tubules. Am J Physiol Cell Physiol. 2000;279:C89-97. 